\title{
Hippocampal stem cells promotes synaptic resistance to the dysfunctional impact of amyloid beta oligomers via secreted exosomes
}

Maria-Adelaide Micci ${ }^{*}$, Balaji Krishnan², Elizabeth Bishop', Wen-Ru Zhang², Jutatip Guptarak', Auston Grant', Olga Zolochevska², Batbayar Tumurbaatar ${ }^{2}$, Whitney Franklin², Claudia Marino², Steven G. Widen ${ }^{3}$, Arjun Luthra ${ }^{4}$, Steven G. Kernie ${ }^{5}$ and Giulio Taglialatela ${ }^{2^{*}}$

\section{Abstract}

Background: Adult hippocampal neurogenesis plays an important role in synaptic plasticity and cogntive function. We reported that higher numbers of neural stem cells (NSC) in the hippocampus of cognitively-intact individuals with high Alzheimer's disease (AD) pathology (plaques and tangles) is associated with decreased synaptic amyloid beta oligomers (ABO), an event linked to onset of dementia in AD. While these findings suggest a link between NSC and synaptic resistance to $A \beta O$, the involved mechanism remains to be determined. With this goal in mind, here we investigated the ability of exosomes secreted from hippocampal NSC to promote synaptic resilience to Aßo.

Methods: Exosomes isolated from media of hippocampus NSC (NSC-exo) or mature hippocampal neuronal (MN-exo) cultures were delivered intracerebroventricularly (ICV) to mice before assessment of Aßo-induced suppression of hippocampal long-term potentiation (LTP) and memory deficits. Aßo binding to synapses was assessed in cultured hippocampal neurons and on synaptosomes isolated from hippocampal slices from wild type mice and from an inducible mouse model of NSC ablation (Nestin- $\delta$-HSV-TK mice) treated with exosomes. Expression of CaMKII and of AMPA and NMDA glutamate receptor subunits in synaptosomes was measured by western blot. Small RNA Deep sequencing was performed to identify microRNAs enriched in NSC-exo as compared to MN-exo. Mimics of select miRNAs were injected ICV.

Results: NSC-exo, but not MN-exo, abolished Aßo-induced suppression of LTP and subsequent memory deficits. Furthermore, in hippocampal slices and cultured neurons, NSC-exo significantly decreased Aßo binding to the synapse. Similarly, transgenic ablation of endogenous NSC increased synaptic Aßo binding, which was reversed by exogenous NSCexo. Phosphorylation of synaptic CaMKII was increased by NSC-exo, while AMPA and NMDA receptors were not affected. Lastly, we identified a set of miRNAs enriched in NSC-exo that, when injected ICV, protected the synapses from Aßo-binding and AßO-induced LTP inhibition.

Conclusions: These results identify a novel mechanism linking NSC-exo and synaptic susceptibility to Aßo that may underscore cognitive resilience of certain individuals with increased neurogenesis in spite of AD neuropathology and unmask a novel target for the development of a new treatment concept for AD centered on promoting synaptic resilience to toxic amyloid proteins.

Keywords: Alzheimer's disease, Aß oligomers, Neural stem cells, Exosomes, Synapses

\footnotetext{
*Correspondence: mmicci@utmb.edu; gtaglial@utmb.edu

'Department of Anesthesiology, University of Texas Medical Branch,

Galveston, TX 77555, USA

${ }^{2}$ Mitchell Center for Neurodegenerative Diseases, Department of Neurology,

University of Texas Medical Branch, Galveston, TX 77555, USA

Full list of author information is available at the end of the article
}



(c) The Author(s). 2019 Open Access This article is distributed under the terms of the Creative Commons Attribution 4.0 International License (http://creativecommons.org/licenses/by/4.0/), which permits unrestricted use, distribution, and reproduction in any medium, provided you give appropriate credit to the original author(s) and the source, provide a link to the Creative Commons license, and indicate if changes were made. The Creative Commons Public Domain Dedication waiver (http://creativecommons.org/publicdomain/zero/1.0/) applies to the data made available in this article, unless otherwise stated. 


\section{Background}

Generation of new neurons from neural stem cells (NSC) has been shown to occur in the dentate gyrus (DG) of the hippocampus [1], a brain region involved in learning and memory and most affected in $\mathrm{AD}$ [2-5]. Although recent reports have re-ignited the discussion on the extent of proliferation of NSC and number of newly generated neurons in the human hippocampus [6, 7], there is ample consensus that neurogenesis contributes significantly to synaptic plasticity and cognitive function [8]. Specifically, reports have shown that while decreased numbers of NSC in the DG result in impairments in learning and memory [9-11], factors known to increase NSC numbers and neurogenesis, such as exercise and environmental enrichment, result in improved learning and memory [12-14]. Notably, impaired neurogenesis is believed to be a key-contributing factor to $\mathrm{AD}$ pathology-driven neuronal dysfunction [15-18].

In the past two decades, the discovery of the existence of individuals who remain cognitively intact despite the presence of neuropathological features (amyloid plaques and tau tangles) normally associated with a fully symptomatic stage of $\mathrm{AD}$ (hereafter referred to as Non-Demented with AD Neuropathology -- NDAN) has significantly impacted the field by revealing that there is a natural way for the brain to resist (or significantly delay) the neurotoxic events that normally lead to cognitive demise in AD (reviewed in Zolochevska and Taglialatela, 2016) [19]. We previously reported that hippocampal synapses in NDAN subjects display a unique proteomic profile [20] and are resistant to the disabling binding of toxic oligomers of amyloid $\beta$ (A $\beta o$ ) [21]. This is significant in that targeting of synapses by toxic $A \beta$ and tau oligomers is reputed to be an early key event in $\mathrm{AD}$, resulting in synaptic disruption that initially drives onset and progression of cognitive decline [22-26]. Therefore, preventing synaptic disruption by amyloid oligomers, as seen in the cognitively intact NDAN subjects, would be an effective therapy for AD. However, a strategy to achieve such a therapeutic objective remains elusive.

In the pursuit of unveiling such a strategy, we have previously reported that NDAN individuals present with a significantly increased number of NSC in the hippocampus DG, as compared to both AD patients and control subjects, and that this increased number of NSC positively correlates with cognitive function [27]. While this was the first report demonstrating such a correlation in the human brain, it was consistent with numerous literature evidences in animal models showing that an increased number of NSC is associated with improved learning and memory [12-14]. Notably, however, contrary to the number of NSC, the number of mature neurons in the DG of NDAN individuals did not correlate with preserved cognition [27], suggesting that the ability of NSC to support cognitive resilience in NDAN is mediated by a mechanism other than their capacity to generate new neurons. While these observations suggest a link between increased NSC numbers and synaptic resistance to $\mathrm{A} \beta$ oligomers toxicity, the involved mechanism remains to be determined.

NSC are known to release large amounts of exosomes $[28,29]$ and recent literature indicates that NSC-derived exosomes (NSC-exo) mediate many of the functional effects classically attributed to these cells [30-32]. Exosomes are small (40-100 nm diameters), secreted vesicles containing cell-specific cargos of proteins, lipids and, most abundantly, regulating microRNAs (miRNAs) [33, 34]. Secreted exosomes are taken up by target cells where they deliver their cargo which modulate cells' function and physiological homeostasis [35]. Exosomes have been shown to mediate the control of ageing speed exerted by hypotalamic NSC [32] and to ameliorate synaptic dysfunction and cognitive decline in the APP/PS1 transgenic AD mouse model [36]. Therefore, signaling via exosome release is emerging as a key feature of NSC, mediating their effects on synaptic and cognitive function and involved in neurodegenerative disorders such as AD. In addition, a recent meta-analysis of comprehensively curated datasets from current relevant literature has shown that exosomes and homeostatic synaptic plasticity are linked to each other and, together, to several neurodegenerative diseases including Huntington's, Parkinson's and AD [37].

Based on this evidence, in the present work we investigated whether exosomes secreted by NSC prevent $\mathrm{A} \beta$ oligomer-driven functional synaptic deficits and memory impairments and whether the mechanism underlying these protective effects by NSC-exo involves increased synaptic resistance to $A \beta$ oligomer binding. Moreover, because miRNAs represent the most abundant exosomal cargo and have been shown to mediate many of the effects elicited by exosomes, including modulation of aging [32], cognition and synaptic function [38-40] and neuroprotection [41], we performed deep sequence analysis to identify select miRNAs uniquely present in NSC-exo (as compared to MN-exo) that could potentially mediate their protective action on synapses of target neurons.

\section{Methods}

\section{Animals}

Mice (C57BL/6 J; 6-8 weeks old) were purchased from Jackson Laboratories (Bar Harbor, ME). Nestin- $\delta$-HSV-TK mice were generated as previously described [42]. Both males and females mice were used in these studies. 


\section{Valganciclovir treatment}

Valganciclovir powder was mixed into mouse chow (0.09\%, Valcyte, valganciclovir hydrochloride) and given ad libitum for an average dose of $\sim 90 \mathrm{mg} / \mathrm{kg} /$ day (Custom Animal Diets, LLC, Easton, PA). Animals were fed either Valganciclovir-containing chow or standard chow ("vehicle") right after weaning for 4 weeks.

\section{Neural stem cells and mature neurons cultures}

Adult rat hippocampus-derived NSC were purchased from MilliporeSigma (Tenecula, CA). NSC were cultured as neurospheres in low-attachment plates in expansion media consisting of: EmbryoMax DMEM/F12 with L-Glutamine, without HEPES, B27-with retinoic acid, GlutaMAX ${ }^{\mathrm{mm}}$ (all from Gibco, ThermoFisher Scientific, Waltham, MA), FGF-b (20 ng/ml, MilliporeSigma, Tenecula, CA) and antibiotics (PSF, Gibco, ThermoFisher Scientific, Waltham, MA). Cells were passaged every 5-7 days using Neuropapain (Genlantis, San Diego, CA). For the generation of mature neurons, NSC neurospheres were dissociated using Neuropapain (Genlantis, San Diego, CA), $2 \mathrm{mg} / \mathrm{ml}$ in basal media, plated out onto poly-ornithine/laminin-coated plates at the density of $8.0 \times 10^{5}$ cells $/ \mathrm{cm}^{2}$ and cultured in differentiation media consisting of expansion media without FGFb and with the addition of $1 \mu \mathrm{M}$ retinoic acid (MilliporeSigma, Tenecula, CA) and $5 \mu \mathrm{M}$ forksolin (MilliporeSigma, Tenecula, CA) for 5 days.

\section{Western blotting analysis of neural stem cells and mature neurons}

Cells growing as neurospheres in complete growth media were collected in a conical tube and centrifuged at $220 \mathrm{~g}$ for $5 \mathrm{~min}$ at room temperature. The cells were washed in Dulbecco's PBS and lysed in RIPA buffer containing protease inhibitors cocktail $\left(200 \mu \mathrm{l}\right.$ of lysis buffer for $<5 \times 10^{6}$ cells). The lysed cells were transferred to $1.5 \mathrm{ml}$ Eppendorf tubes, vortexed and incubated on ice for $20 \mathrm{~min}$. Total protein content was measured using Pierce BCA Protein Assay Kit (Thermo Fisher Scientific, Rockford, IL) and stored at $-20^{\circ} \mathrm{C}$. Cells growing on poly-ornithine/laminin-coated plates were detached using StemPro Accutase, collected into $15 \mathrm{ml}$ tubes and centrifuged at $220 \mathrm{~g}$ for 5 min. The cell pellet was washed in Dulbecco's PBS and lysed in RIPA lysis buffer and total protein content was measured using the Pierce BCA protein assay kit. The protein samples were processed for SDS-polyacrylamide gel electrophoresis (PAGE) with Mini-PROTEAN Tetra Cell System (Bio-Rad, Hercules, CA). After electrophoresis, proteins were transferred to Polyvinylidene Difluoride (PVDF) membranes (Bio-Rad) overnight at $4{ }^{\circ} \mathrm{C}$. Blots were incubated in blocking buffer ( $5 \%$ non-fat dry milk in TBS containing $0.1 \%$ Tween 20; TBS-T) for $1 \mathrm{~h}$ at room temperature and probed with primary antibodies diluted in blocking buffer [1:1000] overnight at $4{ }^{\circ} \mathrm{C}$ (Sox2, Cell Signaling Technology; Nestin, Millipore; NeuN, CellSignaling; $\beta$ III-tubulin, Promega). The membranes were subsequently washed and then incubated for $1 \mathrm{~h}$ with an anti-mouse or anti-rabbit IgG horseradish peroxidase-linked secondary antibody [1:5000] (Cell Signaling Technology). GAPDH was used as a loading control for whole-cell lysate (Invitrogen). Membranes were visualized by incubating for $2 \mathrm{~min}$ in SignalFire Plus ECL Reagent (Cell Signaling Technology, Danvers, MA, USA) followed by chemiluminescence detection on ChemiDoc XRS+ System, Image Lab Software (Bio-Rad, Hercules, CA).

\section{Amyloid $\beta$ oligomers preparation}

Human amyloid $\beta$ ( $\mathrm{A} \beta_{1-42}$ peptide) was purchased from the Department of Biophysics and Biochemistry of Harvard University (MA). Amyloid $\beta$ oligomers were prepared according to established methods [43-45]. Briefly, lyophilized synthetic $A \beta$ aliquots $(0.3 \mathrm{mg})$ were dissolved in $0.2 \mathrm{ml}$ of 1,1,1,3,3,3- Hexafluro-2-propanol (HFP) and subsequently diluted using $700 \mu \mathrm{l}$ of $\mathrm{H}_{2} \mathrm{O}$. A cap with four holes was placed on the tube and the sample was stirred by a magnetic stir bar under a fume hood for $48 \mathrm{~h}$. The sample was used immediately after the 48 $h$ of stirring [43]. Western blot and dot blot analyses using $A \beta$ oligomer specific A-11 antibodies were used to determine the quality of oligomerization as previously described [46] (data not shown).

For the flow cytometry analysis of $\mathrm{A} \beta$ binding to synaptosomes and in vitro binding to cultured hippocampal neurons, fluorescently tagged $\mathrm{A} \beta$ oligomers were prepared by adding $A \beta_{1-42}$ peptide (HiLyteTM Fluor 647 or HiLyteTM Fluor 488, AlexaFluor, AnaSpec Inc.) to HFP-A $\beta$ oligomers. This mixture was then added to $0.7 \mathrm{ml}$ of $\mathrm{H}_{2} \mathrm{O}$ and stirred for $48 \mathrm{~h}$ as described previously [46, 47].

\section{Exosomes isolation and characterization}

Exosomes were isolated from conditioned culture media using the ultracentrifugation method [48, 49]. Briefly, $225 \mathrm{ml}$ of conditioned media collected from approximately 60 million cultured cells (NSC or mature neurons) were centrifuged at $2000 \mathrm{x} \mathrm{g}$, at $4{ }^{\circ} \mathrm{C}$ for $10 \mathrm{~min}$ to remove cells and debris. The resulting supernatant was transferred to new tubes and centrifuged at 10,000 $\mathrm{x} \mathrm{g}$, at $4{ }^{\circ} \mathrm{C}$ for $10 \mathrm{~min}$. The supernatant was transferred to Beckman $60 \mathrm{Ti}$ ultracentrifuge tubes and centrifuged at $126,000 \mathrm{x}$ g for $3 \mathrm{~h}$ at $4{ }^{\circ} \mathrm{C}$. The resulting pellet was resuspended in $2 \mathrm{ml}$ PBS containing a protease inhibitor cocktail (MilliporeSigma, Tenecula, CA), and centrifuged at $135,000 \mathrm{x} \mathrm{g}$ for one hour at $4{ }^{\circ} \mathrm{C}$ in a Beckman TLA110 centrfuge. The resulting pellet, containing exosomes, was resuspended in $1 \mathrm{X}$ PBS containing protease 
inhibitors to a concentration of approximately $10^{9}$ exosomes per microliter.

Comprehensive characterization of isolated exosomes was performed using electron microscopy (EM), western blotting (WB) and nanoparticle tracking analyses. For EM, approximately $5 \mu \mathrm{l}$ of exosome preparation was incubated on carbon film grid (200 mesh, copper), washed, and stained with uranyl acetate. Images were acquired on a Philips CM-100 transmission electron microscope at $60 \mathrm{kV}$ with an Orius SC2001 digital camera (Gatan, Pleasanton, CA). Western blot was performed using $20 \mu \mathrm{l}$ exosome preparation lysed with RIPA buffer containing protease inhibitors. The proteins were separated on a SDS-PAGE gel and transferred to a nitrocellulose membrane. The membrane was probed with primary antibodies against CD9, CD63, CD81, Hsp70 and GM130 (SBI Biotechnology) overnight at $4{ }^{\circ} \mathrm{C}$, followed by IR Dye $680 \mathrm{~nm}$ and $800 \mathrm{~nm}$ secondary antibodies based imaging and quantification (LI-COR Biosciences). Nanoparticle tracking analysis was performed using the NanoSight N300 system and NTA 2.1 operating system (Malvern) according to manufacturer's instructions. Briefly, the exosome preparation was diluted in PBS and injected into the NanoSight for analysis of both particle size and concentration.

\section{Intracerebroventricular (ICV) injections}

Adult (6-8 weeks old) $\mathrm{C} 57 \mathrm{Bl} / 6 \mathrm{~J}$ mice were anesthetized with isoflurane and subjected to ICV injections using the freehand injection method [45, 50, 51]. Briefly, a 29 -gauge needle, firmly held with hemostatic forceps to leave $4.5 \mathrm{~mm}$ of the needle tip exposed, was connected to a $25 \mu \mathrm{l}$ Hamilton syringe via $0.38 \mathrm{~mm}$ polyethylene tubing. Infusions were performed at the rate of $3 \mu \mathrm{l} / \mathrm{min}$ for a total volume of $3 \mu \mathrm{l}$, using an electronic programmable microinfuser (Harvard Apparatus). After ICV injection, the needle was left in place for a minute and the mouse was allowed to recover while lying on a heated pad under warm light.

One day after ICV injection of exosomes (prepared from NSC or MN conditioned media) or PBS (vehicle), mice were treated ICV with $\mathrm{A} \beta \mathrm{o}$ (prepared as described above) and euthanized $24 \mathrm{~h}$ later (for biochemistry and electrophysiology studies) or $48 \mathrm{~h}$ later (at the end of novel object recognition testing) by using deep anesthesia with isoflurane. The brains were removed and processed for fresh hippocampal slices preparation (described in detail below), or further dissected into hippocampi, frontal cortex, parieto-occipital cortex and midbrain, snap frozen on dry ice and stored at $-80^{\circ} \mathrm{C}$ until ready to use for synaptosomes preparation.
Brain slices preparation and electrophysiological assessments of long-term potentiation

Brain slices were prepared according to the method reported by Ting et al. [52] and described below. Mice were deeply anesthetized with isoflurane and transcardially perfused with $25-30 \mathrm{~mL}$ of room temperature carbogenated $\left(95 \% \mathrm{O}_{2}\right.$ and $5 \% \mathrm{CO}_{2}$ gas mixture) NMDG ACSF consisting of $92 \mathrm{mM} \mathrm{NMDG}, 2.5 \mathrm{mM} \mathrm{KCl}, 1.25$ $\mathrm{mM} \mathrm{NaH} \mathrm{NO}_{4}, 30 \mathrm{mM} \mathrm{NaHCO}, 20 \mathrm{mM}$ HEPES, 25 $\mathrm{mM}$ glucose, $2 \mathrm{mM}$ thiourea, $5 \mathrm{mM}$ Na-ascorbate, $3 \mathrm{mM}$ Na-pyruvate, $0.5 \mathrm{mM} \quad \mathrm{CaCl}_{2} \cdot 4 \mathrm{H}_{2} \mathrm{O}$ and $10 \mathrm{mM}$ $\mathrm{MgSO}_{4} \cdot 7 \mathrm{H}_{2} \mathrm{O}$, titrated to $\mathrm{pH} 7.3-7.4$ with $\mathrm{HCl}$. Following perfusion the brains were gently extracted from the skull within one minute. A transverse slicing angle was used to block the brain using super glue to the mounting cylinder to generate slices using the Compresstome VF-300 (Precisionary Instruments) protocols, to get $350 \mu \mathrm{M}$ sections. Using a cut-off plastic Pasteur pipet, an initial protective recovery was done in the cutting solution at $32-34{ }^{\circ} \mathrm{C}$ for $<12 \mathrm{~min}$. The slices were then transferred to a new holding chamber with carbogen saturated HEPES ACSF recovery solution $(92 \mathrm{mM} \mathrm{NaCl}$, $2.5 \mathrm{mM} \mathrm{KCl}, 1.25 \mathrm{mM} \mathrm{NaH}_{2} \mathrm{PO}_{4}, 30 \mathrm{mM} \mathrm{NaHCO} 3,20$ $\mathrm{mM}$ HEPES, $25 \mathrm{mM}$ glucose, $2 \mathrm{mM}$ thiourea, $5 \mathrm{mM}$ Na-ascorbate, $3 \mathrm{mM}$ Na-pyruvate, $2 \mathrm{mM} \mathrm{CaCl} \cdot 4 \mathrm{H}_{2} \mathrm{O}$ and $2 \mathrm{mM} \mathrm{MgSO}_{4} \cdot 7 \mathrm{H}_{2} \mathrm{O}$ ) at room temperature. Recording was done in constantly flowing oxygenated $\left(95 \% \mathrm{O}_{2} /\right.$ $5 \% \mathrm{CO}_{2}$ ) ice-cold normal artificial cerebrospinal fluid (nACSF) consisting of (in mM) $125 \mathrm{NaCl}, 2.5 \mathrm{KCl}, 1.25$ $\mathrm{NaHPO}_{4}, 25 \mathrm{NaHCO}_{3}, 2 \mathrm{CaCl}_{2}, 1.3 \mathrm{MgCl}_{2}$, and $10 \mathrm{dex}-$ trose, $\mathrm{pH}$ 7.3. Slices were perfused at a rate of approximately three $\mathrm{mL} / \mathrm{min}$. Field excitatory post-synaptic potentials (fEPSPs) were collected using an Axon MultiClamp 700B amplifier connected to a Windows computer running Clampex 8.2 software (Molecular Devices). All electrodes were placed under the visual guidance of an upright microscope (Nikon).

The slope from a single fEPSP trace was calculated from the initial slope of the fEPSP relative to the slope of the 10 milliseconds interval immediately preceding afferent stimulation. The current magnitude was delivered through a digital stimulus isolation amplifier (A.M.P.I) and set to elicit a fEPSP approximately $30 \%$ of maximum for synaptic potentiation experiments using platinum-iridium tipped concentric bipolar electrodes (FHC Inc). Using a horizontal P-97 Flaming/Brown Micropipette puller (Sutter Instruments), borosilicate glass capillaries were used to pull electrodes and filled with nACSF to get a resistance of 1-2 M $\Omega$. A stable baseline (for a minimum of ten min) was obtained by delivering single pulse stimulation at $20 \mathrm{~s}$ interstimulus intervals. fEPSPs in the CA1 were evoked by stimulating the Schaffer collaterals (SC: CA3-> CA1) using a conditioning stimulus (CS) 
consisting of three trains of 100 pulses at $100 \mathrm{~Hz}$, twenty seconds apart (high-frequency stimulation; HFS). Input-output experiments were conducted to measure basal dendritic excitation in response to increasing applied current in nACSF. Evoked fEPSP responses were digitized via Digidata $1550 \mathrm{~B}$ and the initial slope of the fEPSP was analyzed using pClamp 10.6 software (Molecular Devices). All data are represented as percentage change from the initial average baseline fEPSP slope, which was defined as the average slope obtained for the ten minutes prior to CS application.

\section{Novel object recognition (NOR) testing}

NOR testing was performed as described previously [47, 50, 53]. Briefly, each mouse was habituated to an empty novel object recognition open field box that served to test each animal for normal locomotion. The sessions commenced with two $10 \mathrm{~min}$ habituation sessions spaced $24 \mathrm{~h}$ apart, during which the TopScan (Clever Sys. Inc., Reston, VA) video-tracking software quantifies various locomotor parameters. Twenty-four hours after the last habituation session, mice were subjected to training in another $10 \mathrm{~min}$ session of exposure to two identical, non-toxic objects (metal or hard plastic items) in the acclimated open field box, so that the animals spent maximum amount of time exploring the objects. The time spent exploring each object was recorded using ObjectScan (Clever Sys. Inc.) by determining a quadrant zone and object zones surrounding the object. After the training session, the animal was returned to its home cage and after a variable retention interval of two hour to twenty-four hours, the animal was returned to the arena in which two objects, one identical to the familiar object but previously unused (to prevent olfactory cues and prevent the necessity to wash objects during experimentation) and one novel object. The animal was allowed ten minutes, during which the amount of time exploring each object was again recorded. Objects were randomized and counterbalanced across animals. The ratio of the difference in time spent exploring each object (familiar versus novel) to the sum of the two was reported as an object discrimination index (ODI). An index above 0.5 is indicative of novelty associated with the object. Each mouse was tested at $2 \mathrm{~h}$ and at $24 \mathrm{~h}$ with the intention of assessing the shorter and longer time frames in memory recall. In order to avoid that the experience in the $2 \mathrm{~h}$ test would affect performance in the $24 \mathrm{~h}$ test, different novel objects were used for the two memory recall tests.

\section{Synaptosomes preparation}

Synaptosomes were isolated using a standardized method developed in the lab [54] and routinely used to assess synaptic dysfunction in our studies [47, 50]. Briefly, brain tissue (snap frozen brain regions: hippocampus, frontal cortex, parieto-occipital cortex and midbrain) [55] or freshly prepared brain slices were homogenized in Syn-PER synaptic protein extraction reagent (ThermoFisher Scientific, Waltham, MA) containing 1X Protease Inhibitor Cocktail (Sigma-Aldrich) and Halt Phosphatase Inhibitor Cocktail (Life Technologies, Inc). A portion of the total homogenate was saved for biochemical analysis and the remaining portion was centrifuged at $1200 \times \mathrm{g}$ for $10 \mathrm{~min}$ at $4{ }^{\circ} \mathrm{C}$. The supernatant was collected and centrifuged further at $15,000 \times \mathrm{g}$ for 20 min at $4{ }^{\circ} \mathrm{C}$. The synaptosomes (contained in the pellet) were resuspended in HEPES-buffered Krebs-like (HBK) buffer (for electron microscopy, ICV and flow cytometry studies) or radioimmunoprecipitation assay (RIPA) buffer (for WB and ELISA studies).

Ultrastructure analysis of synaptosomes was done on $5 \mu \mathrm{L}$ drop adsorbed on 200 mesh coated resin grid (FCF 200 - CU Formavar/Carbon, Electron Microscopy Sciences) and stained with $2 \%$ aqueous uranil acetate for negative staining. Both before and after staining, adsorbed samples were washed three times with DDI water $0.2 \mu \mathrm{m}$ filtered. Resins were blotted with filter paper and dried with warm regular light. Acquisitions were done using a J EM- $140080 \mathrm{KV}$ (Jeol) (Additional file 1: Figure S1A). Synaptosomes were counted using flow cytometry (Guava Easy Cyte 8, Millipore) and correct size between $1 \mu \mathrm{m}$ and $5.6 \mu \mathrm{m}$ for the analysis was chosen using standard size beads as a reference (EMD Millipore) (Additional file 1: Figure S1B).

\section{Quantification of $A \beta$ oligomers binding to synaptosomes ELISA}

The Human $\mathrm{A} \beta 42$ Ultrasensitive ELISA Kit (Invitrogen, Carlsbad, CA), recognizing natural and synthetic human $A \beta 42$, was used to detect $A \beta$ oligomers in isolated synaptosomes. 15,000 synaptosomes or $\sim 0.03 \mu \mathrm{g}$ protein was loaded per well. ELISA was performed according to manufacturer's instructions.

\section{Flow cytometry}

To determine the amount of $A \beta$ oligomers associated with the synaptosomes, two million synaptosomes were incubated with $2.5 \mu \mathrm{M}$ HiLyteTM Fluor 647-labeled A $\beta$ oligomers (HiLyteTM Fluor 647-labeled A $\beta$ - Anaspec Inc., Fremont, $\mathrm{CA}$; $\mathrm{A} \beta$ oligomers - Department of Biophysics and Biochemistry, Yale University, New Haven, $\mathrm{CT}$ ) for $1 \mathrm{~h}$ at room temperature in dark. The samples were washed three times in HBK buffer to remove all unbound $\mathrm{A} \beta$ oligomers and resuspended in PBS without $\mathrm{Ca}^{2+} / \mathrm{Mg}^{2+}$. The samples were analyzed using Guava easyCyte flow cytometer (MilliporeSigma, Burlington, MA). Standard size polystyrene particles (Spherotech, 
Inc., Lake Forest, IL) were used to set up size $1-5 \mu \mathrm{m}$ gate for synaptosomes analyses.

\section{Western blotting analysis of synaptosomes}

Isolated synaptosomes were resuspended in RIPA buffer, protein concentration was measured using BCA (Thermo Fisher Scientific, Waltham, MA). Separation of the proteins in the samples obtained was done by $8 \%$ SDS- polyacrylamide gel electrophoresis. The separated proteins were transferred to a nitrocellulose membrane (Bio-Rad Laboratories, Hercules, CA) and incubated with several antibodies: pGluR1, pGluR2 (1:1000, Abcam, Cambridge, UK); GluR1, NR2B, GluR2, NR1 (1:1000, NeuroMab, UCDavis, CA); pNR2B, pNR1 (1:1000, MilliporeSigma, Burlington, MA); CaMKII, pCaMKII (1:1000, Santa Cruz Biotechnology, Inc., Dallas, TX). $\beta$-actin (1:3000, MilliporeSigma, Burlington, MA) was used as a loading control. The membrane was incubated with proper fluorescent secondary antibodies $(1: 10,000)$ (LI-COR Biosciences, Lincoln, NE) and scanned using Odyssey infrared fluorescent imaging system (LI-COR Biosciences, Lincoln, NE).

\section{$A \beta$ oligomer binding to hippocampal neurons in vitro}

Hippocampal neurons were generated by differentiating adult hippocampal NSC as described above and plated on poly ornithine/laminin-coated plates. Cultures were treated with exosomes (NSCexo or MNexo) or equivalent volume of PBS for $24 \mathrm{~h}$ at $37^{\circ} \mathrm{C}$. After washing, cultures were exposed to $2.5 \mu \mathrm{M}$ Fluor $647-\mathrm{A} \beta$ o or vehicle (PBS) for $30 \mathrm{~min}$ at $37^{\circ} \mathrm{C}$. At the end of the incubation, the cells were washed and fixed in $4 \%$ paraformaldehyde for 15 min. After two washes in PBS, the cells were blocked and permeabilized in PBS containing 5\% normal goat serum for $30 \mathrm{~min}$ at room temperature. The cells were incubated with mouse anti- $\beta$ III-tubulin primary antibody (1:1000, Promega, Madison, WI) diluted in $1.5 \%$ normal goat serum in PBS overnight at $4{ }^{\circ} \mathrm{C}$ in a humid chamber. Following 3 washes in PBS, the cells were incubated with Alexa 488-conjugated anti-mouse secondary antibody (1:400; Invitrogen, Carlsbad, CA) in $1.5 \%$ normal goat serum in PBS for $1 \mathrm{~h}$ at room temperature in a humid chamber. The cells were washed in PBS and coverslipped with Prolong ${ }^{\circ}$ Gold AntiFade Reagent with DAPI (ThermoFisher Scientific, Waltham, MA). Images were acquired with an Olympus confocal microscope (FV1200, Olympus Life Science) and quantification of $\mathrm{A} \beta \mathrm{B}$ binding was performed by an investigator blinded to the experimental groups by counting the number of fluorescent puncta in dendrites using ImageJ software.

\section{Exosomes labelling}

Exosomes were labeled using the PKH26 Red Fluorescent Cell Linker Kit (Sigma-Aldrich, St. Louis, MO).
Briefly, $2 \mu \mathrm{M}$ PKH26 was added to the exosomes suspension and incubated for $4 \mathrm{~min}$ under sterile conditions. After the addition of $1 \% \mathrm{BSA} / \mathrm{PBS}$, the exosomes were centrifuged at $135,000 \times \mathrm{g}$ for one hour at $4{ }^{\circ} \mathrm{C}$ in a Beckman TLA110 and resuspended in PBS and used for subsequent experiments. PKH26-labeled exosomes were injected ICV (as described above) in adult wild type mice (for in vivo tracking) or used for in vitro binding experiments with Fluor 488-labelled Aßo.

\section{Tissue processing and immunofluorescence analysis}

For localization of labelled exosomes in the brain, $4 \mathrm{~h}$ after ICV injection, mice were deeply anesthetized using isoflurane and euthanized. The brains were removed, fresh frozen over dry ice and embedded in O.C.T. compound (Tissue-Tek; Tokyo, Japan). Sections (10 $\mu \mathrm{m}$ thick) were cut on a cryostat (Leica CM 3050S), collected onto Superfrost/Plus slides (ThermoFisher Scientific, Waltham, MA) and stored at $-80^{\circ} \mathrm{C}$ until use. For immunofluorescence, slides were removed from $-80^{\circ} \mathrm{C}$ and fixed in $4 \%$ paraformaldehyde (PF) in $0.1 \mathrm{M} \mathrm{PBS}$, $\mathrm{pH} 7.4$ for $15 \mathrm{~min}$ at room temperature, blocked and permeabilized with $5 \%$ normal goat serum $/ 0.3 \%$ Triton $\mathrm{X}-100 / 0.05 \%$ Tween-20 in PBS, and incubated with rabbit anti-NeuN primary antibody (1:500; Cell Signaling) diluted in PBS containing 1.5\% normal goat serum, overnight at $4{ }^{\circ} \mathrm{C}$. Slides were washed in PBS before incubation with secondary antibodies (Alexa 488 goat anti rabbit; 1:400; Life Technologies) in PBS containing 1.5\% normal goat serum for $1 \mathrm{~h}$ at room temperature. Finally, slides were washed in PBS and coverslipped using Vectashield mounting medium containing DAPI (Vector Laboratories). Images were acquired with an Olympus confocal microscope (FV1200, Olympus Life Science).

For the analysis of eGFP expression in Nestin- $\delta$-HSV-TK mice, animals were trancardially perfused with $4 \% \mathrm{PF}$ and the brains removed and post-fixed in $4 \% \mathrm{PF}$ overnight at $4{ }^{\circ} \mathrm{C}$. The brains were embedded in ascending concentration of glucose solutions $(10,20$, $30 \%$ glucose in PBS) before embedding in OCT compound. Sections $(40 \mu \mathrm{m}$ thick) were cut on a cryostat and collected in antigen preservation solution containing $50 \%$ ethylene glycol and $0.25 \mathrm{M}$ polyvinyl pyrrolidone (ThermoFisher Scientific, Waltham, MA) in PBS and stored at $-20^{\circ} \mathrm{C}$ until ready to use. For immunofluorescence, free-floating sections were washed 3 times in PBS, blocked and permeabilized in 10\% normal goat serum/0.3\% Triton X-100/0.3 M Glycine in PBS $30 \mathrm{~min}$ and incubated with primary antibodies (chicken anti-GFP, 1:1000, Aves and mouse anti-NeuN, 1:400, Invitrogen) in $1.5 \%$ normal goat serum in PBS overnight at $4{ }^{\circ} \mathrm{C}$ for at least $18 \mathrm{~h}$. After washing in PBS contain $0.3 \%$ Tween-20 ( 2 times, 10 min each), sections were incubated with Alexa-conjugated secondary antibodies 
(goat anti-chicken and goat anti-mouse, 1:400; Life Technologies) for $1 \mathrm{~h}$ at room temperature, washed and incubated with a DAPI solution (1:1000) for $5 \mathrm{~min}$, rinsed in distilled water and mounted on microscope slides with FluorSave mounting medium (Calbiochem \# 345789).

\section{Small RNA deep sequencing and $q R T-P C R$ confirmation analysis}

Total RNA was isolated from NSCexo and MNexo using RNAeasy isolation kit (Qiagen, 3 separate preparations for each cell type) and processed for small RNA deep sequencing on an Illumina HiSeq1500 (Next Generation Sequencing Core at UTMB). The global quality of the RNA-seq dataset was tested by checking the reproducibility among technical replicates (Spearman R2 >0.9) and for possible batch effects. Deep sequencing data was analyzed using the mirDeep2 miRNA analysis software suite. This program provides functions for trimming adapter sequences, mapping reads to known miRNAs, predicting novel miRNAs, and quantifying the expression levels of both known and novel miRNAs. Differential expression was analyzed using DESeq2 software.

Quantitative real time PCR with specific TaqMan probes (Applied Biosystems) was used to confirm the expression of miR-17, miR-322 and miR-485. Analysis of the published peer-review literature as well as in silico bioinformatics analysis using several prediction algorithms (TargetScan, GSEA, DESeq2) [56-58] was performed to identify specific miRNAs regulating synaptic function and plasticity.

\section{Intracerebroventricular (ICV) injection of miRNA mimics and target engagement validation}

Wild type mice were injected ICV with miRNA mimics (scrambled, miR-17, miR-322, miR-485) (ThermoFisher Scientific, Waltham, MA) dissolved in ACSF.

Scrambled miRNA was delivered at 1 nmole per mouse, while 0.33 nmole of miR-17, miR-322 and miR-485 were mixed together and a final concentration of 1 nmole of miRNA per mouse was administered. Four animals per group were used. Twenty four hours after ICV injection, RNA was extracted from hippocampi of ICV injected mice using the RNeasy Mini Kit (Qiagen, Venlo, Netherlands) and cDNA was generated with the amfiRivert cDNA Synthesis kit (GenDEPOT, Barker, TX). Quantitative RT-PCR was performed using specific sense and antisense primers for known targets (STAT3, SYN5X, HIFa3) in a $20 \mu$ reaction volume containing $10 \mu \mathrm{l}$ of KAPA SYBR FAST qPCR Master mix (Kapa Biosystems), $0.5 \mu \mathrm{l}$ of $10 \mu \mathrm{mol} / \mathrm{L}$ primer stock, $1 \mu \mathrm{l}$ cDNA, and $8 \mu \mathrm{l}$ double-distilled $\mathrm{H}_{2} \mathrm{O}$. Data were normalized to $\beta$-actin.

\section{A $\beta$ o binding to exosomes in vitro}

A $\beta$ o binding to exosomes was performed according to the procedure described by Yuyama et al, [59]. Briefly, PKH26-labelled exosomes were resuspended in PBS and plated onto chambered glass slides (Thermo Fisher Scientific, Whatman, MA) and allowed to sediment for $1 \mathrm{~h}$ at room temperature. Fluor 488-A $\beta$ o $(1 \mu \mathrm{M})$ were added to the chamber and co-incubated for $5 \mathrm{~h}$ at $37{ }^{\circ} \mathrm{C}$. After a wash with PBS to remove free Aßo, fluorescent images were taken using an Olympus Fluoview FV-10 confocal microscope.

\section{Statistical analysis}

Data is expressed as mean+/- SEM. Analysis of variance (ANOVA) followed by multiple comparisons post-hoc tests were performed using GraphPad Prism software. Behavioral data was analyzed using either one-way ANOVA (Kruskal-Wallis post-hoc test) or repeated measures one or two-way ANOVA followed by a paired or unpaired t-test when significance was achieved. Post-hoc analysis was done using Mann-Whitney U or Wilcoxon matched pair test as appropriate for pair-wise comparison. Statistical significance was defined at $p<0.05$.

\section{Results}

Isolation and characterization of exosomes

In this study, we used exosomes secreted from adult rat hippocampal neural stem cells (NSC) and from mature neurons $(\mathrm{MN})$ obtained by differentiation of the NSC. Immunocytochemistry and western blot analysis confirmed the purity of the cultures by identifying the presence or absence of specific NSC (Sox2 and nestin) and neuronal ( $\beta$ III-tubulin and NeuN) markers (Fig. 1). Exosomes were isolated from the cells' conditioned culture media and characterized using electron microscopy, western blotting and single particle tracking analyses, according to the guidelines of the International Society of Extracellular Vesicles [60, 61]. High-resolution transmission electron micrographs confirmed that exosomes secreted by NSC (NSC-exo) and MN (MN-exo) exhibit rounded and double-membrane structures (Fig. 2a). The purity of the isolation was confirmed by analyzing by western blotting the presence of proteins that are known to be associated with exosomes (CD9, CD63, CD81 and HSP70) and the absence of the Golgi-associated protein GM130 (an important control for cellular contamination) (Fig. 2b). Lastly, single particle tracking analysis using the NanoSight system (Malvern Inc.) showed a bell-shaped curve size distribution profile, indicative of a physically homogeneous population, with an average single peak at $72.3 \mathrm{~nm}$ (NSC-exo) and 69.4 nm (MN-exo) (Fig. 2c). 




Fig. 1 Characterization of hippocampus neural stem cells and mature neurons. Representative phase contrast images of adult rat hippocampus neural stem cells (NSC) maintained in culture as floating neurospheres (a) or differentiated into single-layer mature neurons (MN) (b) as confirmed by the expression of specific makers nestin (c) and BIII-tubulin (d), respectively. Scale bar $=50 \mu \mathrm{m}$. (E) Representative western blot of NSC and MN total protein lysate showing the expression of stem cell markers (nestin and sox2) and the lack of expression of neuronal (NeuN and $\beta I I I-t u b u l i n)$ markers in the NSC, and lack of stem cell markers (nestin and sox2) and expression of neuronal markers (Blll-tubulin and NeuN) in MN. Please note that the western blot in (e) is a composite image of several blots shown here in aggregate for clarity and demonstrative purposes. Images are representative of over 20 independent experiments using hippocampus NSC between passages 6-10

\section{NSC-exo and MN-exo delivered intracerebroventricularly} (ICV) are taken up by neurons

In order to determine the extent to which exogenously-administered exosomes secreted from NSC and $\mathrm{MN}$ enter the brain parenchyma and are taken up by neurons, NSC-exo and MN-exo were labeled with the membrane permeant cell tracker dye PKH-26 and injected ICV in adult wild type mice $\left(3 \times 10^{9}\right.$ exosomes in $3 \mu \mathrm{l}$ of sterile saline). The mice were euthanized $4 \mathrm{~h}$ later and the brains removed and processed for $\mathrm{PKH}-26$ signal detection using confocal microscopy. Numerous PKH-26-labeled exosomes were seen in neuronal cells, identified by NeuN immunoreactivity, in the cortex and hippocampus (Fig. 3).

\section{NSC-exo prevent $A \beta$ oligomer ( $A \beta O)$-induced memory deficits}

In order to test whether exosomes secreted from NSC can protect from Aßo-induced memory impairment, wild type mice were injected ICV with NSC-exo, MN-exo or PBS $24 \mathrm{~h}$ prior to receiving ICV injections of $\mathrm{A} \beta \mathrm{o}(3 \mu \mathrm{L}$ of a $95 \mu \mathrm{M}$ stock) or $\mathrm{PBS}$ $(3 \mu \mathrm{l})$. Four hours later, mice were subjected to the novel object recognition (NOR) training followed by memory recall tests at $2 \mathrm{~h}$ and $24 \mathrm{~h}$ thereafter (see treatment schematic in Fig. 4a). Animals in all groups equally explored the two identical objects during the training phase, indicating no effect of the various treatments on their natural exploratory behavior (Fig. 4b, c). Also, similar to the PBS treatment, ICV injection of MN-exo or NSC-exo alone did not affect the ability of the mice to discriminate between the familiar and the novel object at both 2 and $24 \mathrm{~h}$ memory recall testing times. However, as expected [50], mice treated with PBS or MN-exo that were further injected ICV with A $\mathrm{Ao}$ spent an equal amount of time exploring the familiar and the novel object at both the $2 \mathrm{~h}$ and $24 \mathrm{~h}$ memory recall tests, indicating impaired memory (Fig. 4c). On the other hand, animals that were treated ICV with NSC-exo prior to receiving $\mathrm{A} \beta \mathrm{o}$ spent significantly more time exploring the novel object at both times tested, revealing preserved memory function despite the administration of the toxic A $\beta$ o (Fig. 4b). Representative movement traces of the mice during the NOR testing are shown in Additional file 2: Figure S2.

\section{NSC-exo protect the hippocampus from $A \beta O$-induced suppression of long-term potentiation (LTP)}

In order to investigate the possible cellular basis of the protective effect of NSC-exo on A $\beta$-induced memory deficits, we determined expression of LTP in hippocampal slices prepared from NSC-exo-injected mice and challenged with $\mathrm{A} \beta$ oligomers in a well-established 





(See figure on previous page.)

Fig. 2 Characterization of exosomes isolated from the conditioned medium of neural stem cells (NSC-exo) and mature neurons (MN-exo). a) Representative high-resolution transmission electron microscopy image of exosomes secreted from NSC and from MN, derived from the differentiation of NSC, isolated using the ultra-centrifugation method (scale bar $=100 \mathrm{~nm}$ ). b) Total protein lysates of isolated exosomes were analyzed by western blotting for the presence of exosome-specific proteins, CD63, CD9, HSP70, CD81, and the absence of the Golgi-associated protein GM130 as a control for cellular contamination. Total brain lysate was used as positive control. Please note that the western blot in (B) is a composite image of several blots shown here in aggregate for clarity and demonstrative purposes. Images are representative of over 20 independent experiments using hippocampus NSC between passages 6-10. c) Nanoparticle tracking analysis (NanoSight NS300, Malvern Panalytical, Malvern, UK) of exosomes isolated from NSC and MN shows a homogenous size distribution with an average single peak at $72.3 \mathrm{~nm}$ (NSC-exo) and $69.4 \mathrm{~nm}$ (MN-exo) (data is representative of 3 independent exosome preparations)

protocol of Aßo-driven LTP suppression [45]. NSC-exo or MN-exo $\left(3 \times 10^{9}\right.$ exosomes in $3 \mu \mathrm{l}$ of sterile saline $)$ were injected ICV in wild type mice $4 \mathrm{~h}$ or $24 \mathrm{~h}$ before euthanasia. Hippocampal slices were prepared and treated for one hour with either PBS or preformed $A \beta 0(200 \mathrm{nM})$ (Fig. 5a and Additional file 3: Figure S3). After a stable baseline of $10 \mathrm{~min}$, slices were subjected to high frequency stimulation (HFS) for one minute, and LTP was measured for an hour thereafter. We observed an increase in LTP $(\sim 250 \%)$ in slices from animals treated with PBS, MN-exo or NSC-exo, confirming that exosomes per se did not affect expression of LTP. Treatment of hippocampal slices with A $\beta 0$ significantly reduced expression of LTP ( $150 \%$ ) in brain slices prepared from animals injected with either PBS or MN-exo (Fig. 5c), but not in slices from animals treated with NSC-exo (Fig. 5b). Quantitative assessment of LTP during the last $10 \mathrm{~min}$ of the recording (Fig. 5d) confirmed a statistically significant decrease in HFS-LTP induced by $A \beta 0$ in hippocampus slices from
PBS-treated and MN-exo-treated, but not in slices from NSC-exo-treated animals. This suggests that, consistent with their memory-protecting effects, NSC-exo reduce hippocampal synapses susceptibility to A $\beta$ o-driven LTP dysfunctions.

\section{NSC-derived exosomes promote hippocampal synaptic resistance to $A \beta O$ binding}

Given the observed protective effects of NSC-exo on A $\beta 0$-driven disruption of memory and LTP expression, we investigated whether exosomes secreted from hippocampal NSC can reduce synaptic vulnerability to ABo binding. In these experiments, we elected to treat directly hippocampal slices to exclude possible confounding peripheral effects of exosomes. Freshly prepared hippocampal slices were maintained in ACSF and incubated with PBS, NSC-exo or MN-exo $\left(3 \times 10^{9}\right.$ exosomes in $3 \mu \mathrm{l}$ of sterile saline directly added to the ACSF) for $4 \mathrm{~h}$, consistent with the earliest time resulting in robust


Fig. 3 NSC-exo and MN-exo injected ICV diffuse in the brain parenchyma and are taken up by neuronal cells. Exosomes prepared from the conditioned medium of NSC (NSC-exo) and NSC-derived mature neurons (MN-exo) were labeled with PKH-26 and injected ICV in adult mice four hours before euthanasia. Representative confocal images of mouse brain cross sections showing numerous labeled exosomes (shown in red) in neuronal cells (identified by NeuN immunofluorescence: shown in blue) in the cortex and hippocampus. Images are representative of 3 independent experiments. Calibration bar $=50 \mu \mathrm{m}$ 




uptake of exosomes by neurons (Fig. 3) and protection from Aßo-induced suppression of LTP (Additional file 3: Figure S3). At the end of the incubation, slices were washed 3 times with several volumes of fresh ACSF and further treated with $\mathrm{A} \beta \mathrm{O}(2.5 \mu \mathrm{M})$ for $30 \mathrm{~min}$. ELISA was used to detect bound $A \beta$ in synaptosomes isolated from hippocampal slices. As shown in Fig. 6, the amount of $\mathrm{A} \beta \mathrm{o}$ bound to hippocampal synaptosomes prepared from hippocampal slices treated with NSC-exo was significantly reduced as compared to the amount bound to synaptosomes from slices treated with PBS or MN-exo ( $p<0.05$ NSC-exo vs PBS and MN-exo).

To further test whether NSC-exo-mediated reduction of $\mathrm{A} \beta \mathrm{o}$ binding at the synapse was due to a direct action of the exosomes on the neurons, cultures of mature hippocampus neurons, generated from the differentiation of NSC, were treated with NSC-exo or MN-exo for $24 \mathrm{~h}$. After washing, Fluor 647-Aßo $(2.5 \mu \mathrm{M})$ were 





(See figure on previous page.)

Fig. 5 Aßo-induced suppression of long-term potentiation (LTP) in the hippocampus is abolished by ICV injection of NSC-exo but not by MN-exo. a) Schematic of the experimental design. NSC-exo, MN-exo or PBS (vehicle) were injected icv into adult mice $24 \mathrm{~h}$ before euthanasia. Schaffer collateral field recording of LTP (indicated as percent of baseline in the slope of fEPSPS) was performed on brain slices prepared from NSC-exotreated mice (B) and MN-treated mice (c) in the presence of A oligomers. Control mice were injected with PBS. ABo abolished LTP in PBS treated mice and in MN-exo-treated mice but not in NSC-exo-treated mice. d) The fEPSP amplitude for the final 10 min (time points 50-60 min post high frequency stimulation) were averaged for each condition. A $\beta$ oligomers significantly reduced LTP in brain slices from mice injected with vehicle or with MN-exo, but not in brain slices from mice treated with NSC-exo. N $=6$ mice/group ( 2 slices per mouse). ${ }^{*} p<0.05$ Student's two-tailed T-test.

added to the cultures for $30 \mathrm{~min}$. After washing, the cells were fixed and stained with anti-ßIII-tubulin antibody. Images taken with a confocal microscope revealed, as expected [62, 63], the presence of $A \beta 0$ bound to the dendritic processes (Fig. 7a). Noticeably fewer Aßo were present in cultures pre-treated with NSC-exo, but not with MN-exo. Quantitative analysis performed on images from three independent experiments confirmed that NSC-exo treatment significantly reduced the amount of $\mathrm{A} \beta \mathrm{o}$ bound to the neuronal processes (Fig. $7 \mathrm{~b})$. Thus, these data suggest that decreased $\mathrm{A} \beta \mathrm{\beta o}$ binding occurs in NSC-exo treated neurons.

Lastly, to explore whether endogenous NSC affected synaptic sensitivity to A $\beta$ o, we temporally ablated NSC from the hippocampus of Nestin- $\delta$-HSV-TK-eGFP transgenic mice [42]. This transgenic line contains a modified version of the herpes simplex virus thymidine kinase (TK), as well as an enhanced green fluorescent protein (GFP), driven by the nestin promoter and its second intron regulatory element. Administration of valganciclovir in mouse chow, which is specifically phosphorylated



Fig. 6 NSC-exo, but not MN-exo, reduce hippocampal synaptic vulnerability to $\mathrm{A} \beta \mathrm{B}$ binding. Fresh hippocampal brain slices were prepared from male wt mice and treated with NSC-exo or MN-exo for $4 \mathrm{~h}$ before being challenged with $\mathrm{A} \beta$ oligomers $(2.5 \mu \mathrm{M}$ for 30 $\mathrm{min})$. Synaptosomes were then isolated from each brain slice and the amount of bound $A \beta$ measured using a specific ELISA. $N=3$ mice/group, 3 slices/mouse. ${ }^{*} p<0.05$; Student's two-tailed T-test



B



Fig. 7 NSC-exo, but not MN-exo, reduce synaptic vulnerability to $A \beta O$ binding in hippocampus neurons in vitro. a) Representative confocal microscope images (40X w/3.2 zoom) showing association of $A \beta$ oligomers ( $2.5 \mu \mathrm{m}, 30 \mathrm{~min}$; 647-A $\mathrm{Ao}$, red) to hippocampal neurons ( $\beta$ III-tubulin, green) generated by differentiation of adult rat hippocampus NSC. Nuclei are counterstained blue with DAPI.

Calibration bar $=25 \mu \mathrm{m}$. b) Quantification of the number of 647-Aßo puncta shown in panel $\mathrm{A}$ ( $N=12$ images acquired from 4 independent experiments). ${ }^{* *} p<0.001 ;{ }^{* * *} p<0.0001$ one-way ANOVA $(F=18.95)$ followed by Tukey's multiple comparisons test 
by Nestin- $\delta$-HSV-TK, kills dividing nestin expressing cells in these mice by acting as a toxic thymidine analog. GFP-expressing nestin positive cells in the subgranular layer of the hippocampus and in the subventricular zone of the lateral ventricle (the two main neurogenic zones in the adult rodent brain) were ablated in Nestin$\delta$-HSV-TK-eGFP mice treated with valganciclovir as compared to vehicle-treated mice, confirming the validity of the model (Additional file 4: Figure S4). We then assessed $A \beta O$ binding in vitro, using flow cytometry, in synaptosomes isolated from the hippocampus (HIPP), midbrain (MidB), parieto-occipital cortex (POCX) and frontal cortex (FCX) of Nestin- $\delta$-HSV-TK-eGFP mice treated for 4 weeks with valganciclovir (VGCV) or vehicle. As shown in Fig. 8a, animals lacking resident NSC displayed a significant increase of A $\beta o$ binding in hippocampus, midbrain and frontal cortex as compared to vehicle-treated mice with normal NSC numbers. On the other hand, $\mathrm{A} \beta \mathrm{o}$ binding to parietal cortex synaptosomes was also noticeably increased upon transgenic suppression of NSC but did not reach statistical significance.

In order to determine whether such an increase of synaptic $A \beta O$ binding occurred as a function of reduced levels of NSC-derived exosomes, hippocampus slices were prepared from vehicle-treated and VGCV-treated Nestin- $\delta$-HSV-TK-eGFP mice with ablated NSC and treated with NSC-exo or MN-exo for $4 \mathrm{~h}$. After washing, the slices were further treated with $A \beta O(2.5 \mu M)$ for 30 min and bound $A \beta$ was detected by ELISA in isolated synaptosomes. As shown in Fig. 8b, and consistent with the results shown in Fig. 8a, synaptosomes from VGCV-treated Nestin$\delta$-HSV-TK-eGFP mice showed a significantly increased binding of $\mathrm{A} \beta \mathrm{O}$ as compared to synaptosomes from vehicle-treated Nestin- $\delta$-HSV-TK-eGFP mice with normal NSC numbers. Such increased synaptic vulnerability was corrected by treating the slices with NSC-exo but not with MN-exo prior to exposure to $\mathrm{A} \beta \mathrm{o}$, suggesting that NSC-exo are sufficient to compensate for the loss of endogenous NSC in terms of synaptic sensitivity to $\mathrm{A} \beta \mathrm{O}$.

\section{Phosphorylated (active) CaMKII is increased in the synapses of mice treated ICV with NSC-exo}

In order to determine whether the protective effect of NSC-exo could be in part mediated by changes in the expression and/or activation of proteins relevant to A $\beta$ o-induced toxicity, we isolated hippocampal synaptosomes $24 \mathrm{~h}$ after ICV injection of PBS (vehicle), NSC-exo or MN-exo and analyzed the total protein lysates by western blotting. We found that phosphorylation of $\mathrm{Ca}^{2+} /$ calmodulin-dependent kinase II (CaMKII) was significantly increased in the synaptosomes of mice treated with NSC-exo as compared to MN-exo and vehicle (Fig.9). On the other hand, NSC-exo treatment did not change the expression of AMPA (GluR1, GluR2) and NMDA (NR1, NR2) glutamate receptor subunits at the synaptosome (Additional file 5: Figure S5).

\section{Specific miRNAs in NSC-exo reduce A $\beta$ o binding to the synapse and protect the hippocampus from $A \beta$ o-induced suppression of LTP}

In order to determine whether select miRNAs uniquely present in NSC-exo could mediate their protective action on synapses of target neurons, we performed small RNA Deep sequencing analysis and identified a set of unique miRNAs enriched in NSC-exo, as compared to $\mathrm{MN}$-exo, involved in regulation of synaptic function and plasticity (Additional file 6: Figure S6). Of these unique NSC-exo miRNAs, we selected the most abundant ones (miR-322 and miR-17) along with miR-485 (Fig. 10a). Although miR-485 was enriched in NSC-exo to a lesser extent than miR-322 and miR-17, we included it in our study because in our previous work we have identified it as an upstream regulator of proteomics changes observed at the synapses of human hippocampus autoptic samples from resilient NDAN individuals [20]. Mimics of these miRNAs were injected ICV into wild type mice $24 \mathrm{~h}$ before injection of A 30 . Mice were euthanized $24 \mathrm{~h}$ later. We found that mimics of miR-322 and miR-485 significantly reduced binding of $\mathrm{A} \beta \mathrm{O}$ to hippocampal synaptosomes as compared to scrambled miRNA control, while miR-17 had no effect (Fig. 10b). Notably, we found that when the mice were injected ICV with the combination of all three miRNAs mimics (maintaining the same overall amount of injected RNA), there was a greater decrease of $A \beta O$ association with the synapse (Fig. 10b), pointing to a synergistic effect of the mimics.

In order to test whether reduced $\mathrm{A} \beta \mathrm{o}$ binding resulted in improved synaptic function, we injected ICV a combination of mimics for the three miRNAs (miR-485, miR-17 and miR-322), or the same amount of scrambled RNA, $24 \mathrm{~h}$ before euthanasia. Hippocampal slices were prepared and treated for one hour with either PBS or preformed Aßo (200 nM) (Fig. 11a). After a stable baseline of $10 \mathrm{~min}$, slices were subjected to high frequency stimulation (HFS) for one minute, and LTP was measured for an hour thereafter. We found that $\mathrm{A} \beta \mathrm{o}$-driven reduction of LTP was absent in mice treated with miRNA mimics (Fig. 11b-c).

\section{Discussion}

We report here that in mice, exosomes derived from cultured NSC render neuronal synapses less vulnerable to the binding of toxic $A \beta O$, protect synapses from $\mathrm{A} \beta \mathrm{O}$-induced suppression of LTP expression and prevent memory deficits driven by ICV injection of $A \beta 0$. On the other hand, exosomes derived from MN obtained from 
A

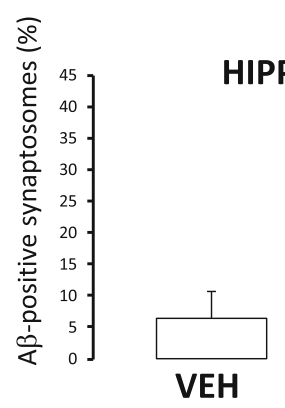

POCX



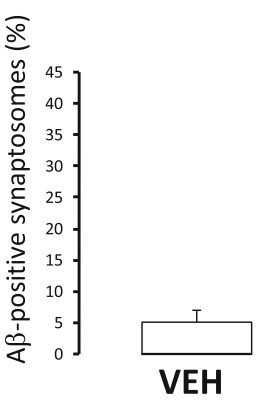

\section{MidB}


HIPPOCAMPUS SYNAPTOSOMES



Fig. 8 Hippocampal synaptic vulnerability to Aßo binding is increased in mice with ablated NSC and this increase is rescued by ICV injection of NSC-exo. a) Nestin- $\delta$-HSV-Tk mice were fed vehicle or valganciclovir (VGCV) chow for 4 weeks. At the end of the 4 weeks, mice were euthanized and synaposomes were isolated from the hippocampus (HIPP), mid brain (MidB), frontal cortex (FCX) and parieto-occipital cortex (POCX) and challenged with Fluor 647-A $\beta$ oligomers $(2.5 \mu \mathrm{M})$ for $30 \mathrm{~min}$. The percent of synaptosomes with bound A $\beta$ was evaluated using flow cytometry. Mice treated with VGCV (with ablated NSC) showed a significant increase in the percent of Aß positive synaptosomes as compared to vehicletreated mice (with intact NSC) in the hippocampus, midbrain and frontal cortex. No statistically significant differences were noted in the parietooccipital cortex. $N=6$ mice/group. ${ }^{*} p<0.05$ Student's two-tailed T-test. b) Nestin- $\delta$-HSV-Tk mice were fed vehicle or valganciclovir (VGCV) chow for 4 weeks. At the end of the 4 weeks, fresh hippocampal brain slices were prepared and treated with NSC-exo or MN-exo for $4 \mathrm{~h}$ before being challenged with $A \beta$ oligomers ( $2.5 \mu \mathrm{M}$ for $30 \mathrm{~min}$ ). ELISA was used to measure the amount of $A \beta$ bound to synaptosomes. $\mathrm{N}=3 \mathrm{mice} / \mathrm{group}$. ${ }^{*} p<0.05 ;{ }^{* *} p<0.01$ one-way ANOVA ( $\left.F=7.276\right)$ followed by Tukey's multiple comparisons test 


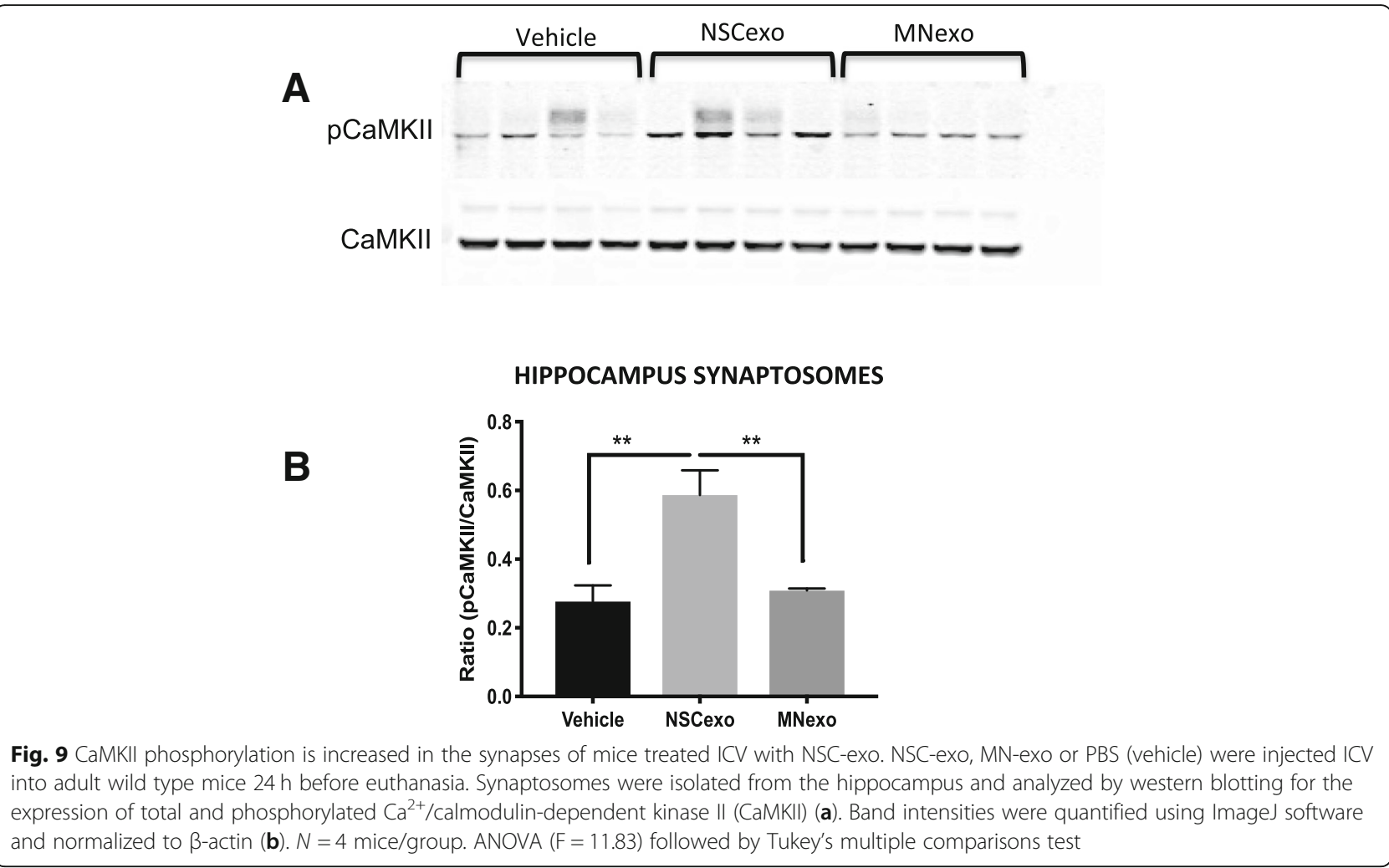

differentiated NSC were not effective. Furthermore, we show that abolishing NSC in the hippocampus DG of inducible Nestin- $\delta$-HSV-TK-eGFP tg mice increases synaptic vulnerability to $\mathrm{A} \beta \mathrm{O}$ and that this phenomenon is reversed by NSC-derived exosomes.
Taken together, these data suggest the existence of a previously unappreciated mechanism whereby endogenous NSC modulate synaptic sensitivity to the dysfunctional binding of $A \beta O$ through local signaling via released exosomes.



Fig. 10 ICV injection of mimics of miRNAs enriched in NSC-exo reduces hippocampal synaptic vulnerability to A 30 binding. a) Relative levels of expression of miR-322, miR-17 and miR-485 in NSC-exo as compared to MN-exo as determined by small RNA deep sequencing. $N=3$ independent NSC-exo or MN-exo preparations each assayed in 3 independent deep sequencing analyses. ${ }^{*} p<0.05$ Student's T-test. b) Mimics of miRNAs (alone or in combination) ( 1 nmole if injected alone or 0.33 nmoles each if injected in combination) or scrambled miRNA as control were injected ICV $24 \mathrm{~h}$ before sacrifice. Hippocampus synaptosomes were prepared and challenged with preformed Aßo (200 nM). After washing, the amount of $A \beta$ in the synaptosomes was quantified by ELISA. ${ }^{*} p<0.05 ;{ }^{* *} P<0.01$ vs. scrambled miRNA. $N=3-4$ mice/group. ${ }^{*} p<0.05 ; p<0.01$ ANOVA $(F=4.796)$ followed by unpaired T-test multiple comparison analysis. 


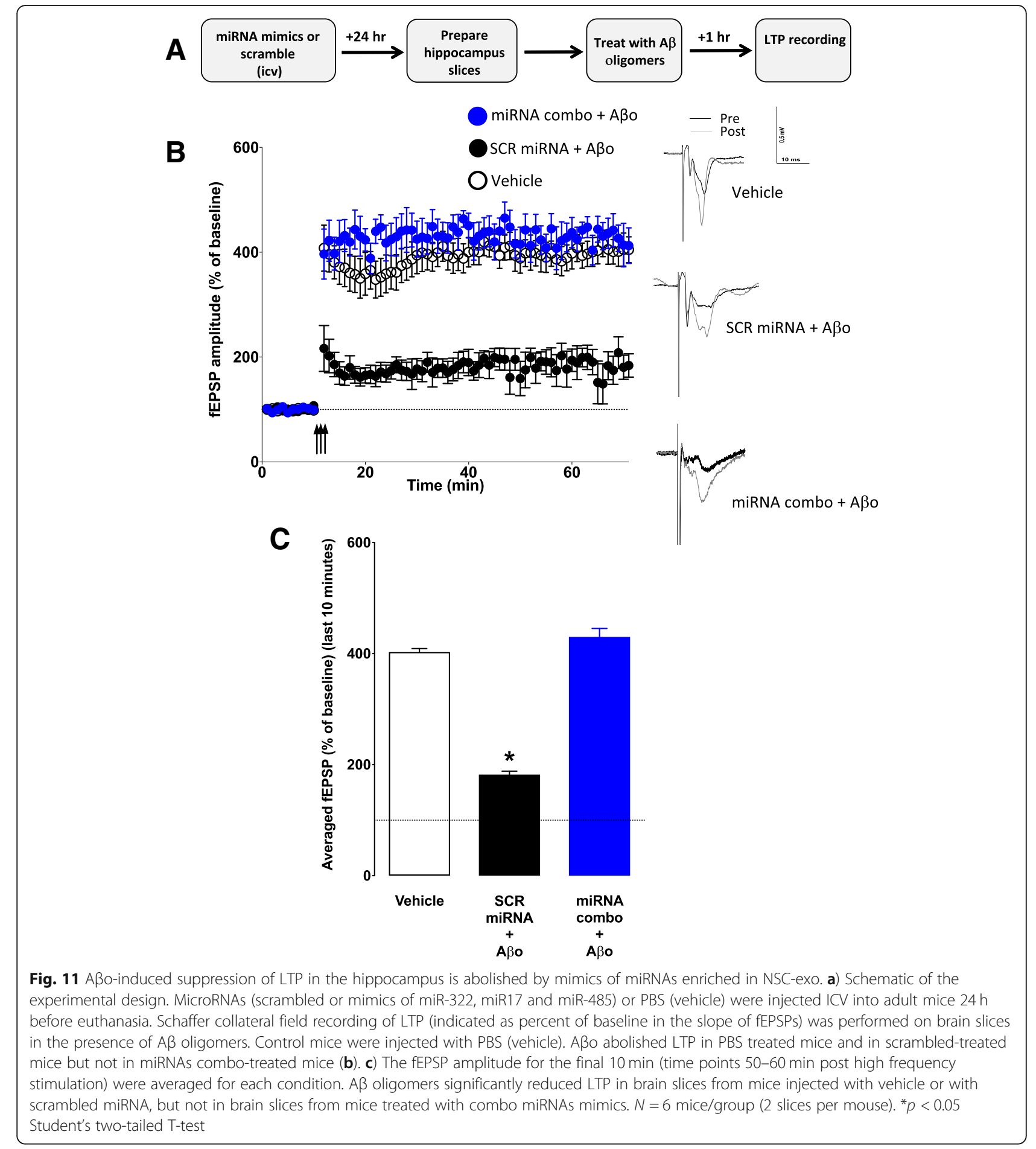

Neurogenesis in the adult brain is known to support synaptic and cognitive function and recent reports from our group have demonstrated a direct correlation between the number of NSC in the hippocampus DG and preserved cognitive function in non-demented individuals with $\mathrm{AD}$ neuropathology (NDAN), suggestive of a protective role of hippocampal NSC [27]. Although this protective effect could be attributed to two main functions of NSC, endocrine secretion and generation of neurons, we have shown that the number of mature neurons in the hippocampus DG of NDAN individuals does not correlate with their preserved cognitive competency [27]. This suggests that the association between increased number of NSC and cognitive resilience in the 
face of $\mathrm{AD}$ pathology is likely mediated by an endocrine secretion mechanism rather than by the NSC ability to generate new neurons. An important endocrine secretion of NSC is constituted by exosomes, intercellular messengers implicated in the transfer of mRNA, miRNAs, proteins and lipids between cells [64]. Here, we show that exosomes secreted from NSC of the hippocampus DG render synapses resistant to $A \beta o$ binding and prevents related dysfunctions (suppression of LTP expression and memory recall deficits). Most importantly, our data show that this mechanism is specific to NSC because exosomes secreted by MN were unable to afford the synapses with a similar protection against $\mathrm{A} \beta \mathrm{o}$. Using exosomes from MN derived from differentiation of NSC, as we did here, is an important strategy because comparing the functional effects of exosomes specifically associated with either a "stem" state or a mature neuronal phenotype of the same cell lineage provides a rigorous scientific control in support of our results, excluding the possibility of non-specific effects of the exosome vesicles such as scavenging of exogenously-added A $\mathrm{\beta}$ o [65, 66]. Moreover, we did not find a significant association between $\mathrm{A} \beta \mathrm{O}$ and exosomes derived from NSC or MN (Additional file 7: Figure S7), thus further supporting our hypothesis that NSC-exo protect against A $\mathrm{Bo}$-mediated toxicity by inducing changes in the recipient neurons. Indeed, we found that phosphorylation (activation) of CaMKII (a critical enzyme for activity-dependent synaptic remodeling associated with cognitive function) [67, 68] is significantly increased at the synapse after ICV treatment with NSC-exo. On the other hand, levels of NMDA and AMPA receptor subunits where not changed at the synaptosomes, indicating that changes in the levels of these receptors known to dock $A \beta 0[69,70]$ may not be a key factor in mediating synaptic resilience to $A \beta O$ afforded by NSC-exo. Rather, more global changes overall resulting in better synaptic function (as reflected by increased pCaMKII) may play a role.

While our data show that exosomes are taken up by neurons and are capable of reducing $\mathrm{A} \beta \mathrm{Bo}$ binding when administered to neuronal cultures, we cannot exclude that they can be taken up by glial cells when injected ICV. Although further studies are necessary to determine whether this is indeed the case and the functional significance of such event, our in vitro data in neuronal cultures clearly demonstrate that uptake of NSC-exo by neurons is sufficient to induce synaptic resistance to $\mathrm{A} \beta \mathrm{o}$ binding.

Binding of $A \beta o$ at the synapses is well-documented to result in disrupted synaptic function, ultimately leading to dendritic spine retraction and cognitive impairments $[25,62]$. Our data show that both synaptic plasticity (LTP) and memory function (NOR test) are protected against $\mathrm{A} \beta \mathrm{O}$-induced deficits in mice treated ICV with NSC-exo (but not MN-exo) prior to challenging with A $\beta$ o. Furthermore, we show that ablation of NSC in an inducible transgenic mouse model leads to increased synaptic vulnerability to $\mathrm{A} \beta$ o that can be over-ridden by exogenous administration of NSC-exo but not MN-exo. Collectively these results indicate that exosomes specifically released by resident NSC play a key role in promoting or maintaining synaptic resilience to the damaging impact of $A \beta$ o that ultimately results in memory deficits. They further suggest the intriguing possibility that a decrease in the number of NSC in the hippocampus DG, such as that occurring during aging [71-73], could lead to increased synaptic vulnerability to the toxic binding of amyloid oligomers, possibly because of reduced NSC-exo signal to neurons. On these bases, it is not unreasonable to envision such a mechanism being one factor linking aging to increased risk of $\mathrm{AD}$ [74], although further studies are needed to ultimately confirm this possibility. Furthermore, exosomes released by affected neurons have been recently investigated in $\mathrm{AD}$ as a possible vehicle of propagation of pathological misfolded proteins, including tau $[75,76]$. Our studies are not in contrast with this view. Rather, we introduce a complementary new concept specifically centered on NSC-secreted exosomes that, rather than being an alternative, provides an additional layer to the still poorly characterized complexity of extracellular vesicles in the CNS and their involvement in AD onset/progression.

MiRNAs are very abundant in exosomes and, in addition to proteins and lipids, represent their main bioactive cargo [77, 78]. Indeed, compelling evidence indicates that many of the effects elicited by exosomes (including NSC-exo) can be ascribed to the action of their specific miRNA cargoes, including modulation of aging [32], cognition and synaptic function [38-40] and neuroprotection [41]. Importantly, miRNAs have been shown to regulate transcriptional modulation of key synaptic proteins within the synaptic compartment itself $[79,80]$. Furthermore, our own previous findings show that resilient hippocampal synapses in NDAN individuals with high numbers of NSCs [27] have a unique proteomic signature [20], suggesting that selective changes in synaptic protein expression (consistent with upstream regulation by specific miRNAs, as revealed by IPA analysis of our proteomic data) mark synaptic resistance to toxic $A \beta$ and tau oligomers in these humans. We found that, as compared to MN-exo, NSC-exo contain a unique set of miRNAs that are known to modulate the expression of proteins involved in synaptic function. Most importantly, we also found that when injected ICV in mice, mimics of such unique NSC-exo derived miRNAs render synapses physically resistant to the detrimental binding of 
$\mathrm{A} \beta \mathrm{O}$ and functionally resilient to their disruptive action. These data support the notion that selected miRNAs uniquely present in NSC-exo could mediate their protective action on synapses of target neurons and further suggests the exciting possibility of new drug discovery to promote cognitive resilience in $\mathrm{AD}$.

\section{Conclusions}

In conclusion, our data point to NSC-secreted exosomes and their miRNAs cargo as one of the critical elements constructing the yet poorly understood neurobiological bases of the complex relationship linking brain reserve to cognitive resilience and resistance to $\mathrm{AD}$ neuropathology. Future pursuing of this novel concept will hopefully open the door to new therapeutic strategies for AD centered on NSC-secreted exosomes and their bioactive cargoes. Indeed, the effect of NSC-secreted exosomes in increasing synaptic resistance to amyloid oligomers has never been documented before and supports the development of a novel and attractive therapeutic strategy aimed at using NSC-secreted exosomes to delay the onset and/or mitigate the severity of A $\mathrm{Bo}$-dependent synaptic and cognitive dysfunctions associated with age-dependent decrease of neurogenesis.

\section{Additional files}

Additional file 1: Figure S1. Characterization of isolated synaptosomes. A) Representative high-resolution transmission electron microscopy images showing the typical morphology of synaptosomes with readily identifiable preserved synaptic structures (white arrows). B) Flow cytometry was used to count synaptosomes. Reference standard size beads (EMD Millipore) were used to gate particle sizes up to $5.6 \mu \mathrm{m}$ for the analysis in order to exclude larger cellular debris. (PPTX $2676 \mathrm{~kb}$ )

Additional file 2: Figure S2. Representative movement traces of mice during the NOR testing Mice treated with NSC-exo $24 \mathrm{~h}$ before ABo ICV injection spent more time exploring the novel object in a manner similar to that of control mice without $A \beta O$ (PBS or exo). On the other hand, mice treated with MN-exo before Aßo ICV injection spent the same amount of time exploring the familiar and the novel objects (indicative of impaired memory). (PPTX $889 \mathrm{~kb}$ )

Additional file 3: Figure S3. ABo-induced suppression of LTP in the hippocampus is abolished by NSC-exo injected ICV four hours earlier. A) Schematic of the experimental design. NSC-exo, MN-exo or PBS (vehicle) were injected ICV into adult mice $4 \mathrm{~h}$ before euthanasia. Schaffer collateral field recording of LTP (indicated as percent of baseline in the slope of fEPSPS) was performed on brain slices prepared from NSC-exo-treated mice $(B)$ and $\mathrm{MN}$-treated mice $(C)$ in the presence of $A \beta$ oligomers. Control mice were injected with PBS. AßO abolished LTP in PBS treated mice and in MN-exo-treated mice but not in NSC-exo-treated mice. D) The fEPSP amplitude for the final $10 \mathrm{~min}$ (time points 50-60 min post high frequency stimulation) were averaged for each condition. $A \beta$ oligomers significantly reduced LTP in brain slices from mice injected with vehicle or with MN-exo, but not in brain slices from mice treated with NSC-exo. $N=6$ mice/group (2 slices per mouse). ${ }^{*} p<0.05$ two-tailed T-test. (PPTX $433 \mathrm{~kb}$ )

Additional file 4: Figure S4. Depletion of hippocampal neural stem cells following treatment of Nestin- $\delta$-HSV-TK mice with valganciclovir. A) Construct scheme for Nestin- $\delta$-HSV-TK transgenic mice. (B-G) Representative images of Nestin- $\delta$-HSV-TK mice brain coronal sections showing the hippocampus dentate gyrus (B-E) and the subventricular zone (SVZ) of the lateral ventricle (F-G) stained with an antibody against green fluorescent protein (GFP, green) and neuronal nuclei (NeuN, red). GFP ${ }^{+}$neural stem cells in the hippocampus dentate gyrus and SVZ are ablated after 4 weeks of Valganciclovir (VGCV) treatment (C, E, G) as compared to mice treated with vehicle (B, D, F). Calibration bar $=100 \mu \mathrm{m}$. (PPTX $1270 \mathrm{~kb}$ )

Additional file 5: Figure S5. Expression of NMDA and AMPA glutamate receptors in hippocampal synaptosomes. Total protein lysates of synaptosomes isolated from the hippocampus of mice injected ICV with PBS (vehicle), NSC-exo or MN-exo were analyzed by western blotting for the expression of total and phosphorylated glutamate AMPA (GluR1 and GluR2) and NMDA (NR1 and NR2) receptors (A). Band intensities were quantified using ImageJ software and normalized to $\beta$-actin. $N=3$. ${ }^{*} p<0.05$ Unpaired T-test. (PPTX $471 \mathrm{~kb}$ )

Additional file 6: Figure S6. Small RNA deep sequencing comparing RNA content in NSC-exo and MN-exo reveals that NSC-exo express a set of unique miRNAs involved in regulation of synaptic function and plasticity. A) Secreted exosomal miRNAs enriched in NSC-exo as compared to MN-exo. B) KEGG pathway analysis $(P<0.05)$ revealed potential target genes of these miRNAs enriched in pathways regulating synaptic function and plasticity. Each bar in blue indicates the number of miRNAs involved in the relevant pathway. The number of regulated genes involved in each pathway is indicated in parenthesis. Data is from 3 separate preparations from each cell type and 3 technical replicates. C) Mimics of miRNAs were injected ICV $24 \mathrm{~h}$ before sacrifice. The efficiency of the delivered mimics was confirmed by measuring levels of specific mRNAs regulated by the selected miRNAs, using RT-PCR. ${ }^{* *} P<0.01$; ${ }^{* * *} P<0.001$; ${ }^{* * *} P<0.0001$ vs. scrambled miRNA (T-test). $N=4$ mice/group. (PPTX $230 \mathrm{~kb}$ )

Additional file 7: Figure S7. Aßo don't associate with NSC-exo and MN-exo. Representative confocal images of PKH26-labelled exosomes (red) after $5 \mathrm{~h}$ incubation with fluorescent $\mathrm{A} \beta$ oligomers (Fluor 488-Aßo, $1 \mu \mathrm{M}$, green). No association of $A \beta 0$ with exosomes is noted. Calibration bar is $10 \mu \mathrm{M}$. (PPTX $383 \mathrm{~kb})$

\section{Abbreviations}

ACSF: Artificial cerebrospinal fluid; AD: Alzheimer's disease; Aßo: Amyloid $\beta$ oligomers; DG: Dentate gyrus; ELISA: Enzyme-linked immunosorbent assay; EM: Electron microscopy; Exo: Exosomes; GFP: Green fluorescent protein; ICV: Intracerebroventricular injection; LTP: Long-term potentiation; miRNA: MicroRNA; MN: Mature neurons; NDAN: Non-demented individuals with AD neuropathology; NOR: Novel object recognition test; NSC: Neural stem cells; PBS: Phosphate buffered saline; RIPA: Radioimmunoprecipitation assay; Tg: Transgenic; WB: Western blotting; Wt: Wild-type

\section{Acknowledgments}

We thank Dr. Vsevolod L. Popov and Ms. Zhixia Ding for helpful suggestions and for the use of the Department of Pathology EM facility.

\section{Funding}

Supported by a grant from the Robert J. Kleberg, Jr., and Helen C. Kleberg Foundation and NIA/NIH 5R01AG042890 and R56AG058281.

\section{Availability of data and materials}

Raw data is available from the corresponding authors upon reasonable request.

\section{Author's contributions}

MAM and GT designed the study, supervised the experiments and wrote the manuscript. BK did ICV injections, performed LTP measurements and behavioral testing and data analysis. EB cultured and characterized NSC and $M N$, performed in vitro binding experiments with $A \beta O$ and exosomes, isolated exosomes and performed EM analyses, extracted RNA for deep sequencing. WRZ isolated exosomes, performed A $\beta$ ELISA assay and WB analyses of synaptosomes. JG sectioned brains and performed immunohistochemistry. EB and AG and AL performed in vitro experiments for $A \beta O$ binding on neuronal cultures and exosomes. OZ performed flow cyotmetry analysis of A $\mathrm{BO}$ binding to synaptosomes. BT performed qRT-PCR analysis of miRNAs in exosomes. WF and CM performed quality control analyses of synaptosomes. SGW performed deep sequencing analysis of exosomal small RNA. SK provided Nestin- $\delta$-HSV-TK-eGFP mice and guided 
their proper experimental use. All authors read and approved the final manuscript.

\section{Ethics approval}

Animal care procedures were approved by the Institutional Animal Care and Use Committee (IACUC) at the University of Texas Medical Branch, Galveston, in accordance with the guidelines provided by the National Institutes of Health.

\section{Consent for publication}

Not applicable.

\section{Competing interests}

The authors declare no competing financial interests.

\section{Publisher's Note}

Springer Nature remains neutral with regard to jurisdictional claims in published maps and institutional affiliations.

\section{Author details}

'Department of Anesthesiology, University of Texas Medical Branch, Galveston, TX 77555, USA. 'Mitchell Center for Neurodegenerative Diseases, Department of Neurology, University of Texas Medical Branch, Galveston, TX 77555, USA. ${ }^{3}$ Biochemistry \& Molecular Biology, University of Texas Medical Branch, Galveston, TX 77555, USA. ${ }^{4}$ Pressent address: The University of Texas at Austin, Austin, TX 78712, USA. ${ }^{5}$ Department of Pediatrics and Pathology \& Cell Biology, Columbia University College of Physicians and Surgeons, New York, NY 10032, USA

\section{Received: 30 October 2018 Accepted: 3 May 2019}

\section{Published online: 14 June 2019}

\section{References}

1. Altman J, Das GD. Autoradiographic and histological evidence of postnata hippocampal neurogenesis in rats. J Comp Neurol. 1965 Jun;124(3):319-35.

2. Barnes J, Bartlett JW, van de Pol LA, Loy CT, Scahill RI, Frost C, et al. A metaanalysis of hippocampal atrophy rates in Alzheimer's disease. Neurobiol Aging. [Meta-Analysis Research Support, N.I.H., Extramural Research Support, Non-U.S. Gov't Review]. 2009 Nov;30(11):1711-23.

3. Appel J, Potter E, Shen Q, Pantol G, Greig MT, Loewenstein D, et al. A comparative analysis of structural brain MRI in the diagnosis of Alzheimer's disease. Behav Neurol. [Research Support, N.I.H., Extramural Research Support, Non-U.S. Gov't Review]. 2009;21(1):13-9.

4. Ohm TG. The dentate gyrus in Alzheimer's disease. Prog Brain Res [Review]. 2007;163:723-40

5. deToledo-Morrell L, Stoub TR, Wang C. Hippocampal atrophy and disconnection in incipient and mild Alzheimer's disease. Prog Brain Res. [Research Support, N.I.H., Extramural Review]. 2007;163:741-53.

6. Boldrini M, Fulmore CA, Tartt AN, Simeon LR, Pavlova I, Poposka V, et al. Human hippocampal neurogenesis persists throughout aging. Cell Stem Cell. 2018;22(4):589-99e5.

7. Sorrells SF, Paredes MF, Cebrian-Silla A, Sandoval K, Qi D, Kelley KW, et al Human hippocampal neurogenesis drops sharply in children to undetectable levels in adults. Nature. 2018 Mar 15;555(7696):377-81.

8. Kempermann G, Gage FH, Aigner L, Song H, Curtis MA, Thuret $\mathrm{S}$, et al. Human Adult Neurogenesis: Evidence and Remaining Questions. Cell Stem Cell. [Review]. 2018

9. Zhao M, Li D, Shimazu K, Zhou YX, Lu B, Deng CX. Fibroblast growth factor receptor-1 is required for long-term potentiation, memory consolidation, and neurogenesis. Biol Psychiatry. [Research Support, N.I.H., Intramural]. 2007 Sep 01;62(5):381-90.

10. Zhao X, Ueba T, Christie BR, Barkho B, McConnell MJ, Nakashima K, et al. Mice lacking methyl-CpG binding protein 1 have deficits in adult neurogenesis and hippocampal function. Proc Natl Acad Sci U S A. [Research Support, Non-U.S. Gov't Research Support, U.S. Gov't, P.H.S.]. 2003 May 27:100(11):6777-82.

11. Ohl F, Fuchs E. Differential effects of chronic stress on memory processes in the tree shrew. Brain Res Cogn Brain Res. 1999 Jan;7(3):379-87.

12. Kempermann G, Kuhn HG, Gage FH. More hippocampal neurons in adult mice living in an enriched environment. Nature. [Research Support, Non-U.S. Gov't]. 1997 Apr 3;386(6624):493-5.
13. van Praag H, Christie BR, Sejnowski TJ, Gage FH. Running enhances neurogenesis, learning, and long-term potentiation in mice. Proc Natl Acad Sci U S A. [Research Support, Non-U.S. Gov't Research Support, U.S. Gov't, P. H.S.]. 1999 Nov 9:96(23):13427-31.

14. van Praag H, Shubert T, Zhao C, Gage FH. Exercise enhances learning and hippocampal neurogenesis in aged mice. J Neurosci. [Comparative Study Research Support, N.I.H., Extramural Research Support, Non-U.S. Gov't Research Support, U.S. Gov't, Non-P.H.S. Research Support, U.S. Gov't, P.H.S.]. 2005 Sep 21:25(38):8680-5.

15. Horgusluoglu E, Nudelman K, Nho K, Saykin AJ. Adult neurogenesis and neurodegenerative diseases: a systems biology perspective. Am J Med Genet B Neuropsychiatr Genet. 2017 Jan;174(1):93-112.

16. Hamilton LK, Joppe SE, L MC, Fernandes KJ. Aging and neurogenesis in the adult forebrain: what we have learned and where we should go from here. Eur J Neurosci. [Research Support, Non-U.S. Gov't Review]. 2013 Jun;37(12):1978-86.

17. Mu Y, Gage FH. Adult hippocampal neurogenesis and its role in Alzheimer's disease. Mol Neurodegener. [Research Support, N.I.H., Extramural Research Support, Non-U.S. Gov't Review]. 2011 Dec 22;6:85.

18. Kuhn HG, Cooper-Kuhn CM, Boekhoorn K, Lucassen PJ. Changes in neurogenesis in dementia and Alzheimer mouse models: are they functionally relevant? Eur Arch Psychiatry Clin Neurosci. [Review]. 2007 Aug;257(5):281-9.

19. Zolochevska O, Taglialatela G. Non-Demented Individuals with Alzheimer's Disease Neuropathology: Resistance to Cognitive Decline May Reveal New Treatment Strategies. Curr Pharm Des. [Review Research Support, Non-U.S. Gov't Research Support, N.I.H., Extramural]. 2016;22(26):4063-8.

20. Zolochevska O, Bjorklund N, Woltjer R, Wiktorowicz JE, Taglialatela G. Postsynaptic proteome of non-demented individuals with Alzheimer's disease neuropathology. J Alzheimers Dis. 2018;65(2):659-82.

21. Bjorklund NL, Reese LC, Sadagoparamanujam VM, Ghirardi V, Woltjer RL, Taglialatela G. Absence of amyloid beta oligomers at the postsynapse and regulated synaptic $\mathrm{Zn} 2+$ in cognitively intact aged individuals with Alzheimer's disease neuropathology. Mol Neurodegener. [Research Support, N.I.H., Extramural]. 2012;7:23.

22. Fa M, Puzzo D, Piacentini $R$, Staniszewski $A$, Zhang $H$, Baltrons $M A$, et al. Extracellular Tau Oligomers Produce An Immediate Impairment of LTP and Memory. Sci Rep. [Research Support, N.I.H., Extramural Research Support, Non-U.S. Gov't]. 2016 Jan 20;6:19393.

23. Selkoe DJ, Hardy J. The amyloid hypothesis of Alzheimer's disease at 25 years. EMBO Mol Med. [Review]. 2016;8(6):595-608.

24. Spires-Jones TL, Hyman BT. The intersection of amyloid beta and tau at synapses in Alzheimer's disease. Neuron. [Research Support, N.I.H., Extramural Research Support, Non-U.S. Gov't Review]. 2014 May 21;82(4):756-71.

25. Tu S, Okamoto S, Lipton SA, Xu H. Oligomeric Abeta-induced synaptic dysfunction in Alzheimer's disease. Mol Neurodegener. [Research Support, N.I.H., Extramural Research Support, Non-U.S. Gov't Research Support, U.S. Gov't, Non-P.H.S. Review]. 2014;9:48

26. Klein WL. Synaptotoxic amyloid-beta oligomers: a molecular basis for the cause, diagnosis, and treatment of Alzheimer's disease? J Alzheimers Dis. [Review]. 2013:33 Suppl 1:S49-65.

27. Briley D, Ghirardi V, Woltjer R, Renck A, Zolochevska O, Taglialatela G, et al. Preserved neurogenesis in non-demented individuals with $A D$ neuropathology. Sci Rep. 2016;6:27812.

28. Stevanato L, Thanabalasundaram L, Vysokov N, Sinden JD. Investigation of Content, Stoichiometry and Transfer of miRNA from Human Neural Stem Cell Line Derived Exosomes. PLoS One. [Research Support, Non-U.S. Gov't]. 2016;11(1):e0146353

29. Marzesco AM, Janich $P$, Wilsch-Brauninger $M$, Dubreuil $V$, Langenfeld $K$, Corbeil D, et al. Release of extracellular membrane particles carrying the stem cell marker prominin-1 (CD133) from neural progenitors and other epithelial cells. J Cell Sci. [Research Support, Non-U.S. Gov't]. 2005 Jul 1; 118(Pt 13):2849-58.

30. Baulch JE, Acharya MM. Allen BD, Ru N. Martirosian V, et al. Cranial grafting of stem cell-derived microvesicles improves cognition and reduces neuropathology in the irradiated brain. Proc Natl Acad Sci U S A: Chmielewski NN; 2016 Apr 4

31. Han C, Sun $X$, Liu L, Jiang $H$, Shen $Y, X u$ X, et al. Exosomes and Their Therapeutic Potentials of Stem Cells. Stem Cells Int. [Review]. 2016;2016: 7653489.

32. Zhang Y, Kim MS, Jia B, Yan J, Zuniga-Hertz JP, Han C, et al. Hypothalamic stem cells control ageing speed partly through exosomal miRNAs. Nature. 2017:548(7665):52-7. 
33. Raposo G, Stoorvogel W. Extracellular vesicles: exosomes, microvesicles, and friends. J Cell Biol. [Research Support, Non-U.S. Gov't Review]. 2013 Feb 18; 200(4):373-83.

34. Sato-Kuwabara Y, Melo SA, Soares FA, Calin GA. The fusion of two worlds: non-coding RNAs and extracellular vesicles--diagnostic and therapeutic implications (Review). Int J Oncol. [Research Support, N.I.H., Extramural Research Support, Non-U.S. Gov't Review]. 2015 Jan;46(1):17-27.

35. Mathivanan S, Ji H, Simpson RJ. Exosomes: extracellular organelles important in intercellular communication. J Proteomics. [Research Support, Non-U.S. Gov't Review]. 2010 Sep 10;73(10):1907-20.

36. Cui GH, Wu J, Mou FF, Xie WH, Wang FB, Wang QL, et al. Exosomes derived from hypoxia-preconditioned mesenchymal stromal cells ameliorate cognitive decline by rescuing synaptic dysfunction and regulating inflammatory responses in APP/PS1 mice. FASEB J. 2018;32(2):654-68.

37. Wang JKT, Langfelder P, Horvath S, Palazzolo MJ. Exosomes and homeostatic synaptic plasticity are linked to each other and to Huntington's, Parkinson's, and other neurodegenerative diseases by database-enabled analyses of comprehensively curated datasets. Front Neurosci. 2017:11:149.

38. Cohen JE, Lee PR, Chen S, Li W, Fields RD. MicroRNA regulation of homeostatic synaptic plasticity. Proc Natl Acad Sci U S A. [Research Support, N.I.H., Extramural Research Support, N.I.H., Intramural]. 2011 Jul 12;108(28):11650-5.

39. Hebert SS, Horre K, Nicolai L, Bergmans B, Papadopoulou AS, Delacourte A, et al. MicroRNA regulation of Alzheimer's Amyloid precursor protein expression. Neurobiology of disease. [Research Support, Non-U.S. Gov't]. 2009 Mar;33(3):422-8.

40. Konecna A, Heraud JE, Schoderboeck L, Raposo AA, Kiebler MA. What are the roles of microRNAs at the mammalian synapse? Neurosci Lett. [Research Support, Non-U.S. Gov't Review]. 2009 Dec 04;466(2):63-8

41. Properzi F, Ferroni E, Poleggi A, Vinci R. The regulation of exosome function in the CNS: implications for neurodegeneration. Swiss Med Wkly. [Research Support, Non-U.S. Gov't Review]. 2015;145:w14204.

42. Yu TS, Zhang G, Liebl DJ, Kernie SG. Traumatic brain injury-induced hippocampal neurogenesis requires activation of early nestin-expressing progenitors. J Neurosci. [Research Support, N.I.H., Extramural]. 2008 Nov 26; 28(48):12901-12

43. Kayed R, Head E, Thompson JL, McIntire TM, Milton SC, Cotman CW, et al. Common structure of soluble amyloid oligomers implies common mechanism of pathogenesis. Science. [Research Support, Non-U.S. Gov't Research Support, U.S. Gov't, P.H.S.]. 2003 Apr 18;300(5618):486-9.

44. Kayed R, Glabe CG. Conformation-dependent anti-amyloid oligomer antibodies. Methods in enzymology. [Research Support, N.I.H., Extramural Research Support, Non-U.S. Gov't]. 2006:413:326-44.

45. Dineley KT, Kayed R, Neugebauer V, Fu Y, Zhang W, Reese LC, et al. Amyloid-beta oligomers impair fear conditioned memory in a calcineurindependent fashion in mice. J Neurosci Res. [Research Support, N.I.H., Extramural Research Support, Non-U.S. Gov't]. 2010 Oct;88(13):2923-32.

46. Reese LC, Zhang W, Dineley KT, Kayed R, Taglialatela G. Selective induction of calcineurin activity and signaling by oligomeric amyloid beta. Aging Cell. [Research Support, N.I.H., Extramural Research Support, Non-U.S. Gov't]. 2008 Dec;7(6):824-35.

47. Comerota MM, Krishnan B, Taglialatela G. Near infrared light decreases synaptic vulnerability to amyloid beta oligomers. Sci Rep. 2017 Nov 8;7(1):15012

48. Greening DW, Xu R, Ji H, Tauro BJ, Simpson RJ. A protocol for exosome isolation and characterization: evaluation of ultracentrifugation, densitygradient separation, and immunoaffinity capture methods. Methods Mol Biol. [Research Support, Non-U.S. Gov't]. 2015;1295:179-209.

49. Lobb RJ, Becker M, Wen SW, Wong CS, Wiegmans AP, Leimgruber A, et al. Optimized exosome isolation protocol for cell culture supernatant and human plasma. J Extracell Vesicles. 2015;4:27031.

50. Krishnan B, Kayed R, Taglialatela G. Elevated phospholipase D isoform 1 in Alzheimer's disease patients' hippocampus: relevance to synaptic dysfunction and memory deficits. Alzheimers Dement. 2018;4:89-102.

51. Clark WG, Vivona CA, Baxter CF. Accurate freehand injection into lateral brain ventricle of the conscious mouse. J Appl Physiol. 1968;25(3):319-21.

52. Ting JT, Daigle TL, Chen Q, Feng G. Acute brain slice methods for adult and aging animals: application of targeted patch clamp analysis and optogenetics. Methods Mol Biol. [Research Support, N.I.H., Extramural Research Support, Non-U.S. Gov't]. 2014;1183:221-42.

53. Taglialatela G, Hogan D, Zhang WR, Dineley KT. Intermediate- and longterm recognition memory deficits in Tg2576 mice are reversed with acute calcineurin inhibition. Behav Brain Res. [Research Support, N.I.H., Extramural]. 2009 Jun 8;200(1):95-9.

54. Franklin W, Taglialatela G. A method to determine insulin responsiveness in synaptosomes isolated from frozen brain tissue. J Neurosci Methods. [Research Support, N.I.H., Extramural Research Support, Non-U.S. Gov't]. 2016 Mar 1;261:128-34.

55. Spijker S. Dissection of rodent brain. Neuroproteomics [Neuromethods]. 2011:57:13-26.

56. Lewis BP, Burge CB, Bartel DP. Conserved seed pairing, often flanked by adenosines, indicates that thousands of human genes are microRNA targets. Cell. [Letter Research Support, Non-U.S. Gov't Research Support, U.S. Gov't, P.H.S.]. 2005 Jan 14;120(1):15-20.

57. Subramanian A, Tamayo P, Mootha VK, Mukherjee S, Ebert BL, Gillette MA, et al. Gene set enrichment analysis: a knowledge-based approach for interpreting genome-wide expression profiles. Proc Natl Acad Sci U S A. 2005;102(43):15545-50.

58. Love Ml, Huber W, Anders S. Moderated estimation of fold change and dispersion for RNA-seq data with DESeq2. Genome Biol. [Research Support, N.I.H., Extramural Research Support, Non-U.S. Gov't]. 2014;15(12):550.

59. Yuyama K, Sun H, Sakai S, Mitsutake S, Okada M, Tahara H, et al. Decreased amyloid-beta pathologies by intracerebral loading of glycosphingolipidenriched exosomes in Alzheimer model mice. J Biol Chem. [Research Support, Non-U.S. Gov't]. 2014 Aug 29;289(35):24488-98.

60. Lotvall J, Hill AF, Hochberg F, Buzas El, Di Vizio D, Gardiner C, et al. Minimal experimental requirements for definition of extracellular vesicles and their functions: a position statement from the International Society for Extracellular Vesicles. J Extracell Vesicles. 2014;3:26913.

61. Witwer KW, Soekmadji C, Hill AF, Wauben MH, Buzas El, Di Vizio D, et al. Updating the MISEV minimal requirements for extracellular vesicle studies: building bridges to reproducibility. J Extracell Vesicles. [Editorial]. 2017;6(1): 1396823.

62. Lacor PN, Buniel MC, Chang L, Fernandez SJ, Gong Y, Viola KL, et al. Synaptic targeting by Alzheimer's-related amyloid beta oligomers. J Neurosci. [Research Support, N.I.H., Extramural Research Support, Non-U.S. Gov't Research Support, U.S. Gov't, P.H.S.]. 2004 Nov 10;24(45):10191-200.

63. Koffie RM, Meyer-Luehmann M, Hashimoto T, Adams KW, Mielke ML, GarciaAlloza $M$, et al. Oligomeric amyloid beta associates with postsynaptic densities and correlates with excitatory synapse loss near senile plaques. Proc Natl Acad Sci U S A. [Research Support, N.I.H., Extramural Research Support, Non-U.S. Gov't]. 2009 Mar 10;106(10):4012-7.

64. Colombo M, Raposo G, Thery C. Biogenesis, secretion, and intercellular interactions of exosomes and other extracellular vesicles. Annu Rev Cell Dev Biol. [Research Support, Non-U.S. Gov't Review]. 2014;30:255-89.

65. An K, Klyubin I, Kim Y, Jung JH, Mably AJ, O'Dowd ST, et al. Exosomes neutralize synaptic-plasticity-disrupting activity of Abeta assemblies in vivo. Mol Brain. [Research Support, Non-U.S. Gov't]. 2013 Nov 13;6:47.

66. Yuyama K, Sun H, Usuki S, Sakai S, Hanamatsu H, Mioka T, et al. A potential function for neuronal exosomes: sequestering intracerebral amyloid-beta peptide. FEBS Lett. [Research Support, Non-U.S. Gov't]. 2015 Jan 02;589(1):84-8.

67. Reese LC, Laezza F, Woltjer R, Taglialatela G. Dysregulated phosphorylation of $\mathrm{Ca}(2+)$ /calmodulin-dependent protein kinase II-alpha in the hippocampus of subjects with mild cognitive impairment and Alzheimer's disease. Journal of neurochemistry. [Research Support, N.I.H., Extramural Research Support, Non-U.S. Gov't]. 2011 Nov;119(4):791-804.

68. Ghosh A, Giese KP. Calcium/calmodulin-dependent kinase II and Alzheimer's disease. Mol Brain. [Research Support, Non-U.S. Gov't Review]. 2015 Nov 24; $8(1): 78$.

69. Decker H, Jurgensen S, Adrover MF, Brito-Moreira J, Bomfim TR, Klein WL, et al. N-methyl-D-aspartate receptors are required for synaptic targeting of Alzheimer's toxic amyloid-beta peptide oligomers. Journal of neurochemistry. [Comparative Study Research Support, Non-U.S. Gov't]. 2010 Dec;115(6):1520-9.

70. Zhao WQ, Santini F, Breese R, Ross D, Zhang XD, Stone DJ, et al. Inhibition of calcineurin-mediated endocytosis and alpha-amino-3-hydroxy-5-methyl-4isoxazolepropionic acid (AMPA) receptors prevents amyloid beta oligomerinduced synaptic disruption. J Biol Chem. 2010 Mar 5;285(10):7619-32.

71. Lugert S, Basak O, Knuckles P, Haussler U, Fabel K, Gotz M, et al. Quiescent and active hippocampal neural stem cells with distinct morphologies respond selectively to physiological and pathological stimuli and aging. Cell Stem Cell. [Research Support, Non-U.S. Gov't]. 2010 May 7;6(5):445-56. 
72. Kuhn HG, Dickinson-Anson H, Gage FH. Neurogenesis in the dentate gyrus of the adult rat: age-related decrease of neuronal progenitor proliferation. J Neurosci. [Comparative Study Research Support, Non-U.S. Gov't Research Support, U.S. Gov't, P.H.S.]. 1996 Mar 15;16(6):2027-33.

73. Ben Abdallah NM, Slomianka L, Vyssotski AL, Lipp HP. Early age-related changes in adult hippocampal neurogenesis in C57 mice. Neurobiol Aging. [Research Support, Non-U.S. Gov't]. 2010 Jan;31 (1):151-61.

74. Querfurth HW, LaFerla FM. Alzheimer's disease. N Engl J Med. [Review]. 2010 Jan 28:362(4):329-44

75. Wood H. Alzheimer disease: Evidence for trans-synaptic and exo-synaptic tau propagation in Alzheimer disease. Nat Rev Neurol. [Comment]. 2015 Dec;11(12):665.

76. Polanco JC, Scicluna BJ, Hill AF, Gotz J. Extracellular Vesicles Isolated from the Brains of rTg4510 Mice Seed Tau Protein Aggregation in a Thresholddependent Manner. J Biol Chem. [Research Support, Non-U.S. Gov't]. 2016 Jun 10;291 (24):12445-66.

77. van den Boorn JG, Dassler J, Coch C, Schlee M, Hartmann G. Exosomes as nucleic acid nanocarriers. Adv Drug Deliv Rev. [Review]. 2013 Mar;65(3):331-5.

78. Bayraktar R, Van Roosbroeck K, Calin GA. Cell-to-cell communication: microRNAs as hormones. Mol Oncol. [Review]. 2017 Dec;11(12):1673-86.

79. Schratt G microRNAs at the synapse. Nat Rev Neurosci. [Research Support, Non-U.S. Gov't Review]. 2009 Dec;10(12):842-9.

80. Garza-Manero S, Pichardo-Casas I, Arias C, Vaca L, Zepeda A. Selective distribution and dynamic modulation of miRNAs in the synapse and its possible role in Alzheimer's Disease. Brain Res. [Research Support, Non-U.S. Gov't Review]. $2014 ; 1584: 80-93$.

Ready to submit your research? Choose BMC and benefit from:

- fast, convenient online submission

- thorough peer review by experienced researchers in your field

- rapid publication on acceptance

- support for research data, including large and complex data types

- gold Open Access which fosters wider collaboration and increased citations

- maximum visibility for your research: over $100 \mathrm{M}$ website views per year

At $\mathrm{BMC}$, research is always in progress.

Learn more biomedcentral.com/submissions 